\title{
Chemical Nature of Microfluidically Synthesized AuPd Nanoalloys Supported on $\mathrm{TiO}_{2}$
}

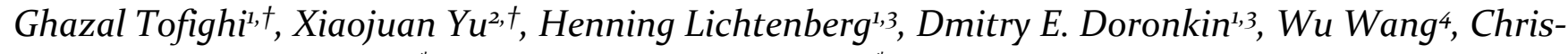 \\ tof Wöll', Yuemin Wang, , and Jan-Dierk Grunwaldt ${ }^{1,3,},{ }^{2}$
}

${ }^{1}$ Institute for Chemical Technology and Polymer Chemistry (ITCP), Karlsruhe Institute of Technology (KIT), D76131 Karlsruhe, Germany

${ }^{2}$ Institute of Functional Interfaces (IFG), Karlsruhe Institute of Technology (KIT), D-76344 EggensteinLeopoldshafen, Germany

3 Institute of Catalysis Research and Technology (IKFT), Karlsruhe Institute of Technology (KIT), D-76344 Eggenstein-Leopoldshafen, Germany

${ }^{4}$ Institute of Nanotechnology (INT), Karlsruhe Institute of Technology (KIT), D-76344 Eggenstein-Leopoldshafen, Germany

\begin{abstract}
Metal oxide supported bimetallic AuPd nanoparticles (NPs) are known to exhibit significantly enhanced activity and selectivity in numerous reactions compared to their monometallic counterparts. An atomic-level understanding of the nature of AuPd nanoalloys is among the most important and challenging topics in catalysis and nanoscience. Here, colloidal monometallic $\mathrm{Au}$ and Pd as well as bimetallic $\mathrm{Au}_{\mathrm{x}} \mathrm{Pd}_{\mathrm{y}} \mathrm{NPs}(\sim 1 \mathrm{~nm})$ with different $\mathrm{Au}$ :Pd ratios were synthesized in a continuous microfluidic reactor and then deposited on $\mathrm{TiO}_{2}$. The structural, electronic and reactive properties of $\mathrm{Au}_{\mathrm{x}} \mathrm{Pd}_{\mathrm{y}} / \mathrm{TiO}_{2}$ were first investigated by a multi-technique approach including scanning transmission electron microscopy, energy dispersive X-ray spectroscopy mapping, in situ X-ray absorption spectroscopy, FTIR spectroscopy, and X-ray photoelectron spectroscopy. Temperature-dependent IR spectroscopy using $\mathrm{CO}$ as a probe molecule provided deeper and solid evidence for the presence of a variety of active sites on the surface of monometallic Au and Pd NPs and $\mathrm{Au}_{\mathrm{x}} \mathrm{Pd}_{\mathrm{y}}$ nanoalloys. The results demonstrated consistently strong electronic interactions between $\mathrm{Au}$ and Pd upon alloying, leading to an interatomic charge transfer and electronic modifications in the d bands of $\mathrm{Au}$ and $\mathrm{Pd}$. The $\mathrm{AuPd} / \mathrm{TiO}{ }_{2}$ sample with an Au:Pd ratio of 3:7 exhibited the highest catalytic activity in CO oxidation compared to the other alloys. This was attributed to a synergistic effect where the activation of dioxygen is facilitated at the Pd-enriched sites while both bimetallic $\mathrm{Au}$ and Pd sites chemisorb CO. Hence, the combination of microfluidic synthesis and advanced characterization including FTIR allowed deeper insights into the nature of AuPd nanoalloys for catalytic applications.
\end{abstract}

\section{Introduction}

For a long time, the most noble among all metals, gold, was not expected to exhibit significant catalytic activity. ${ }^{1-4}$ However, in the early 1990 s Haruta et al. and then also other research groups ${ }^{5}$ demonstrated that small Au nanoparticles (NPs) with diameters of ${ }^{1-5} \mathrm{~nm}$, deposited on suitable support materials, are active in low temperature $\mathrm{CO}$ oxidation $^{6-8}$ and selective oxidation of propylene to propylene oxide in the presence of oxygen and hydrogen.9-10 Since then, catalytic properties of Au NPs have attracted much attention with respect to many applications such as water-gas shift (WGS) reactions ${ }^{11-12}$, reduction of nitrogen oxides ${ }^{13-14}$, oxidation of alcohols ${ }^{5},{ }^{15}, \mathrm{H}_{2} \mathrm{O}_{2}$ synthesis from $\mathrm{H}_{2}$ and $\mathrm{O}_{2}{ }^{11,}{ }^{15}$, aerobic oxidation of alcohol $^{16-17}$, selective hydrogenation of alkenes ${ }^{11}$ etc. Particle size affects two essential factors for the catalytic activity of supported gold NPs: the number of low-coordination sites and the total length of perimeter sites at the metalsupport interfaces. So far, it has been difficult to unambiguously distinguish these two effects, and unraveling the importance of the individual contributions to the synergistic catalytic performance remains to be a major challenge. Additionally, quantum size effects resulting from confining the metal electrons and strain effects reducing the lattice constant of small metal particles may contribute to the chemical activity of ultrasmall metal particles. ${ }^{1}$ 18-19

Alternatively, various catalytic properties can be obtained by combining different metals to synthesize intermetallic compounds and nanoalloys. ${ }^{20-21}$ Alloying often leads to synergistic effects resulting in higher catalytic activity, and the variety of alloys with different compositions, structures and properties gives many degrees of freedom to design bi- or trimetallic catalysts for particular applications, especially in the field of structure-sensitive reactions. ${ }^{22-23}$ Bimetallic AuPd catalysts have been extensively applied for synthesis of vinyl acetate $e^{24-25}, \mathrm{H}_{2} \mathrm{O}_{2}{ }^{26-28}$ as well as alcohol and glucose oxidation..$^{29-32}$ Moreover, as $\mathrm{Pd}$ is already a key element in the well-established three-way catalyst due to its high $\mathrm{CO}$ oxidation activity at elevated 
temperatures 33 , addition of Pd to Au-based catalysts could be beneficial to improve the catalytic performance and durability of gold at high temperatures, while also inhibiting Au NP aggregation. ${ }^{34-35}$ With respect to $\mathrm{CO}$ oxidation, several publications reported that $\mathrm{O}_{2}$ dissociation, which in $\mathrm{Au} / \mathrm{TiO}_{2}$ takes place at the interface of $\mathrm{Au}$ and $\mathrm{TiO}_{2}{ }^{1,}{ }^{8}$, could be facilitated by the presence of Pd. In some cases, such bimetallic systems were found to exhibit improved stability and higher catalytic activity at low temperatures compared to monometallic Au and Pd catalysts. $34-36$ However, details of the involved mechanisms for charge transfer in small nanoalloys are still unclear. A deeper understanding requires a combination of well-defined homogeneous nanoalloy materials and advanced characterization techniques.

The homogeneity of the alloy particles, or the extent of segregation, is strongly influenced by the synthesis procedure and post-synthetic treatment such as precursors, temperature and pressure, and also on the nanoalloy composition. Within the interdisciplinary field of colloidal chemistry, NPs with tailored physical and chemical properties determined by particle size and shape can be synthesized. ${ }^{20}, 37$ Apart from conventional-stirred batch reactors, microfluidic reactors equipped with micromixers are able to achieve homogeneous and efficient mixing of the reactants at a short time scales (ms). These advantages have attracted considerable attention in recent years, and microfluidic systems are of pronounced interest as novel, powerful devices to produce monometallic and alloyed NPs in a profoundly controlled manner. This allows tailoring particle sizes, structures (e.g. homogeneous nanoalloys, core-(multi)- shell and segregated subcluster structures), and achieving narrow size distributions of the nanoalloys, a requirement for further tuning the desired catalytic properties..$^{38-40}$

Recently, we have studied the synthesis of Au and Pd NPs and also homogeneous $\mathrm{Au}_{\mathrm{x}} \mathrm{Pd}_{\mathrm{y}}$ nanoalloys inside a novel microfluidic reactor ${ }^{41}$. For the present study (note that this work was conducted in the frame of the $\mathrm{PhD}$ thesis by Ghazal Tofighi ${ }^{42}$ ), such bimetallic NPs were deposited on $\mathrm{TiO}_{2}$, and the effects of alloying and Au-Pd interaction on surface properties. Next, the electronic structure and morphology were investigated using a multi-technique approach. Employing a novel ultrahigh-vacuum Fouriertransform infrared spectroscopy (UHV-FTIR) apparatus ${ }^{43}$, a systematic in situ IR study using $\mathrm{CO}$ as probe molecule on $\mathrm{Au} / \mathrm{TiO}_{2}, \mathrm{Pd} / \mathrm{TiO}_{2}$, and $\mathrm{Au}_{\mathrm{x}} \mathrm{Pd}_{\mathrm{y}} / \mathrm{TiO}_{2}$ at different temperatures was conducted on these well characterized systems. The temperature-dependent FTIRS data in conjunctions with high-resolution XPS results provided new insights into the chemical nature of the Au-Pd interaction, allowing us to substantially advance the understanding of the mechanisms governing $\mathrm{CO}$ oxidation reactions on supported alloy particles.

\section{Experimental Section}

\subsection{Materials}

$\mathrm{HAuCl}_{4} \cdot{ }_{3} \mathrm{H}_{2} \mathrm{O}$ (Roth, 99.5\% purity), $\mathrm{K}_{2} \mathrm{PdCl}_{4}$ (Alfa Aesar, 99.99\% purity), polyvinylpyrrolidone (Sigma-Aldrich, average molecular weight $40 \mathrm{kDa}$ ), $\mathrm{NaBH}_{4}$ (SigmaAldrich, $99.99 \%$ purity), $\mathrm{H}_{2} \mathrm{SO}_{4}$ (Sigma-Aldrich, $95 \%$ purity) and $\mathrm{TiO}_{2}$ (Evonik, commercially available Aeroxide P25 , anatase:rutile phase ratio of $80: 20$, surface area of 50 $\mathrm{m}^{2} \mathrm{~g}^{-1}$ ) were used without further purification.

\subsection{Microfluidic Reactor}

In previous work ${ }^{41}, 44$, we have introduced a novel microfluidic setup providing a continuous flow of reactants at high flow rates which was successfully employed to synthesize highly monodisperse and ultrasmall $\mathrm{Au}, \mathrm{Pd}$ and AuPd NPs. The setup shown in Figure 1 features a fluid delivery rack and a microfluidic chip consisting of $3 \mathrm{cy}$ clone micromixers and a meandering microchannel. A nitrogen gas pressure of 13 bar acts as a driving force for the flow of reactants stored in corrosion-resistant stainless steel vessels. The vessel for the metal precursor solution is coated with polyethylene. For each reactant, a flow rate of $1.3 \mathrm{~L} \mathrm{~h}^{-1}$ was applied to approach turbulent mixing conditions for the reactant flow in the micromixers with a Reynolds number of 2400 (total flow rate $2.6 \mathrm{~L} \mathrm{~h}^{-1}$ ). This provides efficient mixing in $2 \mathrm{~ms}$ which is essential for such rapid reduction reactions. The total residence time of the reactants in the microfluidic device amounts to 20 ms. The microfluidic chip consists of Si-bonded glass. Inlet and outlet ports and the cylinders for the cyclone micromixers were produced by laser drilling. The meandering channel (cross section: $300 \times 300 \mu \mathrm{m}^{2}$ ) was produced by Si etching. The design of the microfluidic chip also allows in situ characterization of the NPs during synthesis using spectroscopic and scattering techniques.

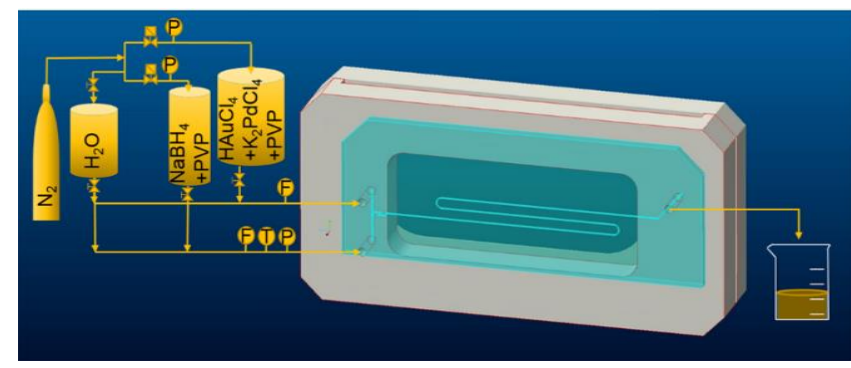

Figure 1. Schematic of the microfluidic setup including reactant vessels and microfluidic chip for synthesis of the metal NPs and nanoalloys in continuous flow (F, T and P: Flowmeter, temperature sensor and pressure transducer). The microfluidic chip made of Si-glass bonded wafer is sandwiched between the stainless steel support parts.

\subsection{Microfluidic Synthesis of Au, Pd and AuPd Nano- particles}

Monometallic Au and Pd NPs as well as AuPd nanoalloys were synthesized following a previously published procedure ${ }^{40-41}$. In this colloidal route, the metal precursors are reduced under basic conditions (via $\mathrm{NaBH}_{4}$ ) in the presence of PVP as a surfactant. Typically, an aqueous solution of mixed $\mathrm{Au}$ and Pd precursors $(7.5 \mathrm{mM})$ with 666 mg PVP was prepared for all samples. The nominal molar Au:Pd ratio was 1:0, 7:3, 1:1, 3:7 and 0:1. A basic aqueous solution of $\mathrm{NaBH}_{4}(37.5 \mathrm{mM})$ with $666 \mathrm{mg}$ PVP was prepared as the reducing agent. These two solutions were poured separately into the corresponding vessels of the 
microfluidic setup. A total flow rate of $2.6 \mathrm{~L} \mathrm{~h}^{-1}$ (turbulent regime) at 13 bar $\mathrm{N}_{2}$ pressure (due to the high pressure drop) was used to push the reactants through the micromixers and the microchannel. Afterwards, the nanoparticles were collected in a flask and magnetically stirred for 1 $\mathrm{h}$ in an ice/water bath.

\subsection{Preparation of $\mathrm{Au} / \mathrm{TiO}_{2}, \mathrm{Pd} / \mathrm{TiO}_{2}$ and $\mathrm{AuPd} / \mathrm{TiO}_{2}$ Catalysts}

After dispersing $1 \mathrm{~g} \mathrm{TiO}_{2}$ in $80 \mathrm{~mL}$ distilled water in an ultrasonic bath, the colloidal NPs obtained from the microfluidic reactor were added to the suspension at room temperature and stirred for $1 \mathrm{~h}$. Before impregnating $\mathrm{TiO}_{2}$ with the NPs, the support was acidified with o.1 mL pure $\mathrm{H}_{2} \mathrm{SO}_{4}$ solution (suspension $\mathrm{pH}: 2$ ). Subsequently, the suspension was centrifuged 4 times (4500 rpm, $5 \mathrm{~min}$ each) and washed with $\mathrm{H}_{2} \mathrm{O}$ in between. Finally, the catalysts were dried at $353 \mathrm{~K}$ overnight and calcined at $673 \mathrm{~K}$ for $3 \mathrm{~h}$ in static air. This method was applied for preparing 2.4 wt. $\% \mathrm{Au} / \mathrm{TiO}_{2}, \mathrm{Pd} / \mathrm{TiO}_{2}$ and $\mathrm{Au}_{\mathrm{x}} \mathrm{Pd}_{\mathrm{y}} / \mathrm{TiO}_{2}$.

\subsection{Characterization}

\subsubsection{Transmission Electron Microscopy}

The catalyst powder samples were directly dispersed on $\mathrm{Cu}$ grids coated with holey carbon film. For colloid samples, $5 \mu \mathrm{l}$ of the diluted colloidal solution was dropped on a holey carbon $\mathrm{Cu}$ grid covered with $2 \mathrm{~nm}$ carbon film and then dried at room temperature. Microstructure and morphology of the sample materials were investigated by high resolution transmission electron microscopy (HRTEM) and high angle annular dark-field (HAADF) scanning transmission electron microscopy (STEM). Composition was determined by energy dispersive X-ray spectroscopy (EDX) using an EDAX S-UTW EDX detector in a FEI Titan 8o-300 microscope operating at $300 \mathrm{kV}$. Particle size statistics of the specimens were determined from the HAADF-STEM images by the ImageJ 1.49v software. Particle shaped were approximated with ellipsoids. ${ }^{45}$ STEM-EDX data were analyzed by the TEM Image \& Analysis (TIA 4.7 $\mathrm{SP}_{3}$ version) software.

\subsubsection{X-Ray Absorption Near Edge Structure (XANES)}

XANES spectra of $\mathrm{Pd} / \mathrm{TiO}_{2}$ and $\mathrm{AuPd} / \mathrm{TiO}_{2}$ pellets at the Pd K-edge (24.350 keV) were acquired at room temperature in transmission mode at CAT-ACT ${ }^{46}$, a new wiggler beamline recently installed at the Karlsruhe Institute of Technology, using a Si (311) double crystal monochromator (beam size $1 \times 1 \mathrm{~mm}^{2}$ ) and ionization chambers. Higher harmonics were suppressed by a Rh-coated mirror downstream from the monochromator. Under the same conditions XANES data of the powder samples were acquired in situ (in quartz capillaries) under $\mathrm{N}_{2}$ flow $(33 \mathrm{ml}$ $\mathrm{min}^{-1}$ flow rate) during heating to $673 \mathrm{~K}$ at $5 \mathrm{~K} \mathrm{~min}^{-1}$. For raw data treatment the Athena program of the IFEFFIT software package ${ }^{47}$ was used.

\subsubsection{FTIR Spectroscopy and X-Ray Photoelectron Spectroscopy (XPS)}

The FTIRS and XPS measurements were performed with a sophisticated ultra-high vacuum (UHV) setup, combing a vacuum FTIR spectrometer (Bruker Vertex 8ov) and a multi-chamber UHV system (Prevac). This apparatus allows both IR reflection-absorption spectroscopy (IRRAS) on model systems and IR transmission on powders. ${ }^{48-49}$ The $\mathrm{Au}_{\mathrm{x}} \mathrm{Pd}_{\mathrm{y}} / \mathrm{TiO}_{2}$ powder samples were first pressed into an inert metal grid and then mounted on a sample holder specifically designed for temperature-dependent FTIR transmission measurements. Prior to the IR measurements, the samples were pre-treated by annealing at 673 $\mathrm{K}$ for $1 \mathrm{~h}$ under UHV conditions. Oxidation states were monitored using an XPS apparatus equipped with a VG Scienta 44000 electron energy analyzer before IR measurements. Al $K_{\alpha}$ (nonmonochromatic, $1486.6 \mathrm{eV}$ ) radiation was used as excitation source. The energy resolution was better than $1 \mathrm{eV}$ with a pass energy of $200 \mathrm{eV}$. The binding energies were calibrated based on the $\mathrm{C}_{1}$ line at $284.8 \mathrm{eV}$ as a reference. The XP spectra were deconvoluted using the Casa XPS program with a GaussianLorentzian mix function, a Doniach-Sunjic function for metallic $\mathrm{Pd}^{\circ}$ species,,$^{\circ}$ and Shirley background subtraction. For a quantitative analysis of the relative surface concentration of $\mathrm{Au}$ and $\mathrm{Pd}$, sensitivity factors of 9.58 for Au $4 f_{7 / 2}$ and 9.48 for $\mathrm{Pd} 3 \mathrm{~d}_{5 / 2}$ were used..$^{11}$

The $\mathrm{TiO}_{2}$-supported metal particles were exposed to $\mathrm{CO}$ by using a leak-valve-based directional doser connected to a tube (inner diameter: $2 \mathrm{~mm}$ ) terminating at a distance of $3 \mathrm{~cm}$ from the sample. IR spectra were recorded with a resolution of $4 \mathrm{~cm}^{-1}$ by using a spectrum of the clean sample as background reference. The temperaturedependent FTIR spectra were quantitatively analyzed by peak fittings in order to obtain normalized peak areas as a function of temperature.

\subsubsection{CO Oxidation Test Procedure}

$\mathrm{CO}$ oxidation was chosen as test reaction to assess the catalytic performance of the $\mathrm{TiO}_{2}$ supported metal NPs. $\mathrm{CO}$ oxidation experiments were performed two times after two different pre-treatment procedures: exposure to $\mathrm{N}_{2}$ at $673 \mathrm{~K}$ for $1 \mathrm{~h}$ and $\mathrm{H}_{2}$ pre-treatment $\left(5 \% \mathrm{H}_{2}\right.$ in $\left.\mathrm{N}_{2}\right)$ at $523 \mathrm{~K}$ for $1 \mathrm{~h}$ (10 K min ${ }^{-1}$ ramp rate in both cases). During the tests the catalysts were heated in a fixed-bed continuous-flow reactor (quartz tube, inner diameter $8 \mathrm{~mm}$ ) in a temperature programmed mode from $303 \mathrm{~K}$ to $523 \mathrm{~K}$ at a ramp rate of $1 \mathrm{~K} \mathrm{~min}^{-1} .70 \mathrm{mg}$ of 2.4 wt. $\% \mathrm{Au}_{\mathrm{x}} \mathrm{Pd}_{\mathrm{y}} / \mathrm{TiO}_{2}$ catalysts (sieve fraction $125^{-250} \mu \mathrm{m}$ ) were mixed with $930 \mathrm{mg}$ $\mathrm{SiO}_{2}$ and then fixed between glass wool plugs in the tube

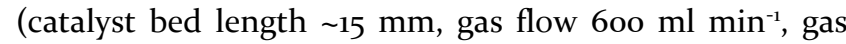
hourly space velocity, GHSV: $\left.48000 \mathrm{~h}^{-1}\right)$. The gas mixture contained $1000 \mathrm{ppm} \mathrm{CO}$ and $10 \% \mathrm{O}_{2}$ in nitrogen (CO feed rate: $5.8 \times 10^{-6} \mathrm{~mol} \mathrm{~s}^{-1} \mathrm{~g}^{-1}$ cat). The gas feed passed through a Messer Hydrosorb $b^{\circ}$ cartridge to remove traces of water before reaching the reactor. Reaction products were analyzed using a URAS $10 E$ NDIR $\mathrm{CO} / \mathrm{CO}_{2}$ analyzer. Each heating and cooling cycle was applied twice. Only the data acquired during the second cycle are shown in this paper. Turnover frequencies (TOFs) were calculated in the region between $3-17 \% \mathrm{CO}$ conversion (for $\mathrm{Au} / \mathrm{TiO}_{2}$ below $40 \%$ in the temperature range of $323-336 \mathrm{~K}$ ) and based on the assumption that the reaction rate (r) did not depend on the $\mathrm{CO}$ concentration. ${ }^{8}$ For TOF calculations 
the metal dispersion was estimated from mean NP diameters (determined by STEM).

\section{Results and Discussion}

\subsection{Electron Microscopy and in situ XANES Spectros- copy under $\mathrm{N}_{2}$ Flow}

The different mono- and bimetallic NPs were all deposited on the same well-defined $\mathrm{TiO}_{2}$ support in order to keep all parameters besides NP composition identical for comparability. STEM images allow characterizing particle shapes and sizes, as well as their aggregation, upon deposition and calcination. As an example, STEM images of colloidal $\mathrm{Au}_{7} \mathrm{Pd}_{3} \mathrm{NPs}$, supported/dried on $\mathrm{TiO}_{2}$ and calcined sample with their corresponding histograms are shown in Figure Si. In this case, the average particle size increases from about $1 \mathrm{~nm}$ to $4 \mathrm{~nm}$ upon deposition on $\mathrm{TiO}_{2}$ and further to $5 \mathrm{~nm}$ after calcination. A series of STEM images (Figure S2) shows the particle morphology and size distribution of NPs at different compositions deposited on $\mathrm{TiO}_{2}$ after calcination at $673 \mathrm{~K}$. The alloyed $\mathrm{Au}_{\mathrm{x}} \mathrm{Pd}_{\mathrm{y}} \mathrm{NPs}$, in particular the Au-rich alloys $\left(\mathrm{Au}_{7} \mathrm{Pd}_{3}\right.$ and $\mathrm{Au}_{5} \mathrm{Pd}_{5}$ ) are notably smaller ( 5 and $6 \mathrm{~nm}$ ) with narrower size distributions compared to $\mathrm{Au} / \mathrm{TiO}_{2}(11 \mathrm{~nm})$. Due to low contrast in STEM image between oxidized Pd and the $\mathrm{TiO}_{2}$ support in the calcined $\mathrm{Pd} / \mathrm{TiO}_{2}$ sample, the Pd NPs could not be unambiguously detected by electron microscopy. In case of $\mathrm{Au}_{3} \mathrm{Pd}_{7} / \mathrm{TiO}_{2}$, precise determination of particle sizes is also difficult due to a segregated contiguous surface layer at the perimeter of the NPs on the support. STEM-EDX mapping (Figure 2) detected Pd in this segregated layer. Obviously, besides some Pd segregated out of the NPs, a certain amount of Pd is also located at the NP core together with $\mathrm{Au}$, in accordance with the results of previous works. ${ }^{41}$ The HRTEM images of calcined $\mathrm{Au} / \mathrm{TiO}_{2}, \mathrm{Au}_{7} \mathrm{Pd}_{3} / \mathrm{TiO}_{2}$ and $\mathrm{Au}_{3} \mathrm{Pd}_{7} / \mathrm{TiO}_{2}$ catalysts in Figure $\mathrm{S}_{3}$ reveal the atomic structure of $\mathrm{Au}, \mathrm{Au}_{7} \mathrm{Pd}_{3}$ and $\mathrm{Au}_{3} \mathrm{Pd}_{7} \mathrm{NPs}$. The measured d-spacing of the (111) lattice planes within $\mathrm{Au}_{7} \mathrm{Pd}_{3} / \mathrm{TiO}_{2}$ and $\mathrm{Au}_{3} \mathrm{Pd}_{7} / \mathrm{TiO}_{2}$ catalysts is slightly smaller compared to $\mathrm{Au} / \mathrm{TiO}_{2}(\mathrm{~d}$-spacing $(111)=2.33$ $\AA ̊$ ) indicating a presence of alloy structure of AuPd NPs. ${ }^{41}$, ${ }^{52}$ In the Au-rich alloys, Au and Pd are distributed uniformly in the NPs. STEM images and elemental mapping indicate that, under the applied preparation conditions, alloying reduces NP agglomeration compared to monometallic Au and Pd NPs, and additionally keeps the Pd with $\mathrm{Au}$ in the nanoparticles, which could influence the catalytic performance.

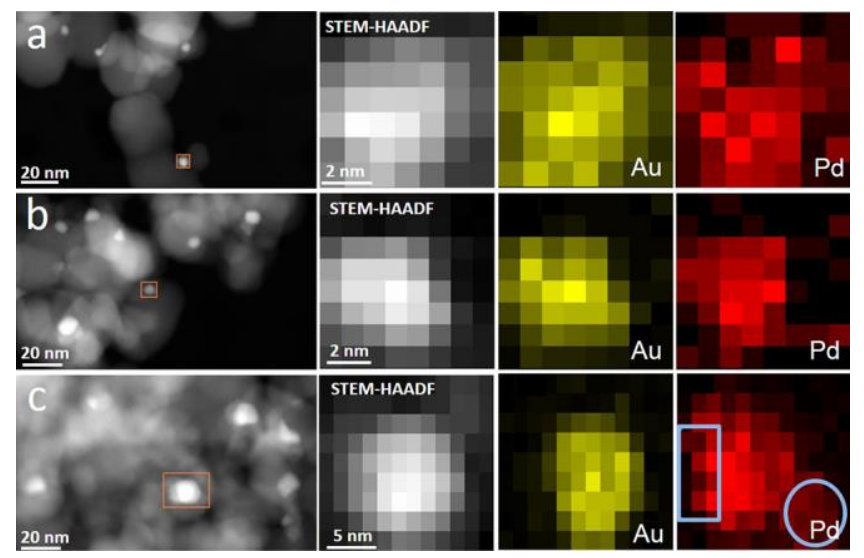

Figure 2. STEM-EDX mapping of calcined (a) $\mathrm{Au}_{7} \mathrm{Pd}_{3}$, (b) $\mathrm{Au}_{5} \mathrm{Pd}_{5}$ and $(\mathrm{c}) \mathrm{Au}_{3} \mathrm{Pd}_{7}$ supported on $\mathrm{TiO}_{2}$.

In order to determine the initial oxidation state of $\mathrm{Pd}$ in calcined $\mathrm{Pd} / \mathrm{TiO}_{2}$ and $\mathrm{AuPd} / \mathrm{TiO}_{2}$ catalysts and to monitor changes in oxidation state during the annealing treatment (UHV, heating up to $673 \mathrm{~K}$ for $1 \mathrm{~h}$ and cooling down to room temperature), the samples were investigated by in situ XANES spectroscopy under $\mathrm{N}_{2}$ gas flow during heating up to $673 \mathrm{~K}$ and cooling down to room temperature. Figure $\mathrm{S}_{4}$ shows selected spectra acquired during heating. The results indicate that oxidized palladium dominates in both samples at all temperatures. A comparable trend was also observed during cooling. Figure $\mathrm{S}_{4}$ shows that the spectra of the NP samples clearly differ from the absorption data of a Pd foil representing metallic Pd (i.e. oxidation state zero). The same applies to the ex situ Pd K-edge XANES data of pellet samples (see Figure $S_{5 a}$ ) which also show that with increasing Au content in the alloyed NPs, Pd gets more reduced (in accordance with FTIR results in section 3.3). The corresponding $\mathrm{Au} \mathrm{L}_{3}$-edge in Figure $\mathrm{S}_{5} \mathrm{~b}$ shows a lower whiteline intensity for the alloyed AuPd compared to the Au NPs, in accordance with literature.4, 53

\subsection{XPS Data}

Figure 3 shows $\mathrm{Au} 4 \mathrm{f}$ and $\mathrm{Pd}$ 3d XP spectra of various $\mathrm{Au}_{\mathrm{x}} \mathrm{Pd}_{\mathrm{y}} / \mathrm{TiO}_{2}$ samples (x:y = 1:0, 7:3, 1:1, 3:7, o:1) pre-treated by annealing at $673 \mathrm{~K}$ for $1 \mathrm{~h}$ under UHV conditions. The monometallic $\mathrm{Au} / \mathrm{TiO}_{2}$ exhibits two spin-orbit components $\left(4 \mathrm{f}_{7 / 2}\right.$ and $\left.4 \mathrm{f}_{5 / 2}\right)$ at 84.0 and $87.7 \mathrm{eV}$ (Figure 3a), which are characteristic of the neutral $\mathrm{Au}^{\circ}$ species; the corresponding Au $4 \mathrm{~d}_{5 / 2}$ peak is located at $335.2 \mathrm{eV}$. For the pure $\mathrm{Pd}$ and all AuPd alloy samples, metallic $\mathrm{Pd}^{\circ}$ was identified as majority species based on the dominating doublet at 335.3 $\left(\mathrm{Pd} 3 \mathrm{~d}_{5 / 2}\right)$ and $340.6 \mathrm{eV}\left(\mathrm{Pd}_{3} \mathrm{~d}_{3 / 2}\right.$, Figure $3 b)$. Additionally, the monometallic Pd and Pd-rich (70\%) alloy NPs show another doublet at 337.1 and $342.4 \mathrm{eV}$, revealing the presence of some minority $\mathrm{Pd}^{2+}$ species.54-57 It should be noted that in the core-level Pd $3 \mathrm{~d}$ spectra, the relatively broad $\mathrm{Au} 4 \mathrm{~d}_{5 / 2}$ peak at $335.2 \mathrm{eV}$ is clearly resolved for the gold-rich (50\% and $70 \%$ ) alloys although it overlaps with the $\mathrm{Pd} 3 \mathrm{~d}_{5 / 2}$ component.

On the basis of a quantitative analysis of the XPS data, the atomic ratios between $\mathrm{Au}$ and Pd were estimated. The results revealed a slightly higher Pd content for the 
$\mathrm{Au}_{\mathrm{x}} \mathrm{Pd}_{\mathrm{y}} / \mathrm{TiO}_{2}$ samples when compared to the initial synthesis ratio (Table 1 ), indicating an enrichment of all alloy surfaces with $\mathrm{Pd}$, in line with the literature. ${ }^{24,}{ }^{41}$ The concentration of $\mathrm{Pd}^{2+}$ was estimated as approx. $10 \%$ for monometallic $\mathrm{Pd} / \mathrm{TiO}_{2}$ and approx. $4.4 \%$ for Pd-enriched $\mathrm{Au}_{3} \mathrm{Pd}_{7} / \mathrm{TiO}_{2}$. The $\mathrm{Pd}^{2+}$ species presumably result from activation of dioxygen at the surface of pure $\mathrm{Pd}$ and at the $\mathrm{Pd}$-enriched sites of $\mathrm{Au}_{3} \mathrm{Pd}_{7} / \mathrm{TiO}_{2}$. Indeed, in case of $\mathrm{Au}$ rich $\left(\mathrm{Au}_{5} \mathrm{Pd}_{5} / \mathrm{TiO}_{2}\right.$ and $\left.\mathrm{Au}_{7} \mathrm{Pd}_{3} / \mathrm{TiO}_{2}\right)$ samples, where the $\mathrm{Pd}$ atoms are incorporated as $\mathrm{Pd}^{\circ}$ in an AuPd alloy structure, $\mathrm{Pd}^{2+}$ species were not observed. Alloying Au with $\mathrm{Pd}$ tends to shift the electron density toward the element with the larger fraction of empty valence states. ${ }^{8}$ Figure 3a shows that for $\mathrm{Au}_{3} \mathrm{Pd}_{7} / \mathrm{TiO}_{2}$ the $\mathrm{Au} 4 \mathrm{f}$ doublet shifts to lower binding energies (83.7 and $87.4 \mathrm{eV}$ ) upon alloying with Pd. This finding is attributed to the charge transfer from $\mathrm{Pd}$ to $\mathrm{Au}$ because $\mathrm{Au}$ is more electronegative. ${ }^{34}$, 40, 59${ }_{60}$ The electronic interaction between $\mathrm{Au}$ and $\mathrm{Pd}$ in the alloy is of complex nature. It has also been proposed that $\mathrm{Au}$ gains $s p$ valence electrons and loses $d$ electrons whereas Pd loses $s p$ electrons and gains $d$ electrons. ${ }^{8,}$, 61-63 According to Wang et al., Au obtains 6s conduction charge in AuPd bimetallics accompanied by a slight $5 \mathrm{~d}$ charge depletion. ${ }^{64}$ The electronic perturbation in the $d$ bands of Pd and Au was corroborated by the IR results shown below.

Table 1. Atomic Ratios of the $\mathrm{Au}_{\mathrm{x}} \mathrm{Pd}_{\mathrm{y}} / \mathrm{TiO}_{2}$ Based on XPS Results.

\begin{tabular}{lll}
\hline Sample & $\mathrm{Au}(\%)$ & $\mathrm{Pd}(\%)$ \\
\hline $\mathrm{Pd}$ & $\mathrm{o}$ & $100\left(\mathrm{Pd}^{\circ}: \mathrm{Pd}^{2+}=90: 10\right)$ \\
$\mathrm{Au}_{3} \mathrm{Pd}_{7}$ & 21.5 & $78.5\left(\mathrm{Pd}^{\circ}: \mathrm{Pd}^{2+}=74.1: 4.4\right)$ \\
$\mathrm{Au}_{5} \mathrm{Pd}_{5}$ & 36.6 & $63.4\left(\mathrm{Pd}^{\circ}\right)$ \\
$\mathrm{Au}_{7} \mathrm{Pd}_{3}$ & 56 & $44\left(\mathrm{Pd}^{\circ}\right)$ \\
$\mathrm{Au}$ & 100 & $\mathrm{o}$ \\
\hline
\end{tabular}
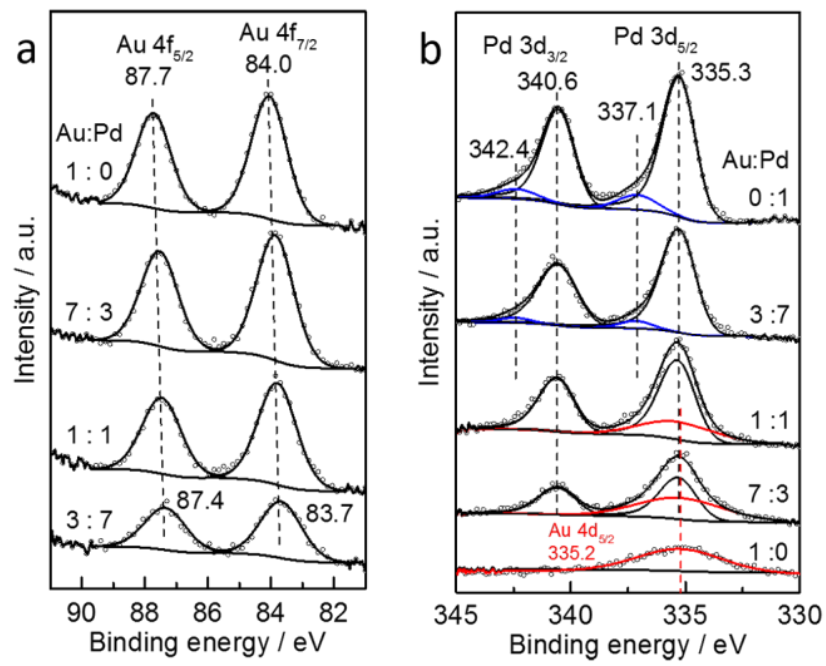

Figure 3. Deconvoluted X-ray photoelectron spectra of $\mathrm{Au}_{\mathrm{x}} \mathrm{Pd}_{\mathrm{y}} / \mathrm{TiO}_{2}$ samples (x:y = 1:0, 7:3, 1:1, 3:7, o:1): (a) $\mathrm{Au} 4 \mathrm{f}$ region and (b) Pd $3 d$ region. 

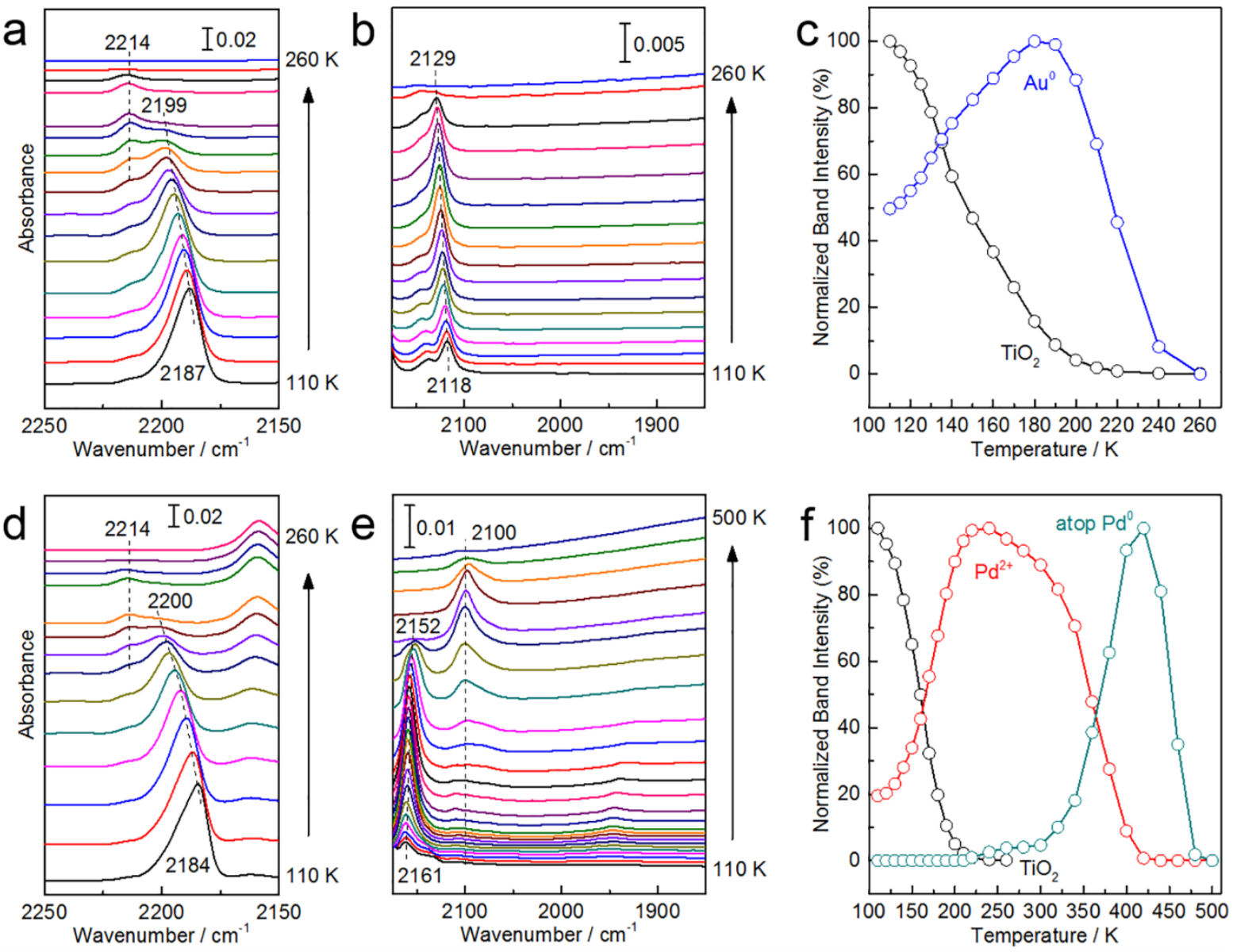

Figure 4. FTIR spectra recorded after exposing the $\mathrm{Au} / \mathrm{TiO}_{2}(\mathrm{a}-\mathrm{c})$ and $\mathrm{Pd} / \mathrm{TiO}_{2}$ (d-f) samples to $4 \times 10^{-3} \mathrm{mbar} \mathrm{CO}$ at $110 \mathrm{~K}$ and then heating gradually; (a, d) $\mathrm{CO}-\mathrm{TiO}_{2}$ region, (b) $\mathrm{CO}-\mathrm{Au}$ region, (e) $\mathrm{CO}-\mathrm{Pd}$ region and (c, f) normalized band intensity attributed to $\mathrm{CO}$ bound to different surface adsorption sites as a function of sample temperature.

\subsection{Temperature-dependent FTIR Spectroscopy with CO as Probe Molecule}

The surface properties and chemical states of various $\mathrm{Au}_{\mathrm{x}} \mathrm{Pd}_{\mathrm{y}} / \mathrm{TiO}_{2}$ samples were further characterized by FTIR spectroscopy using $\mathrm{CO}$ as a probe molecule (Figures 4 and 5). In contrast to XANES and XPS, the adsorbed CO speciesprobe exclusively metal species $(\mathrm{Ti}, \mathrm{Au}, \mathrm{Pd})$ present at the very surface of the samples. For all $\mathrm{TiO}_{2}$-supported catalysts, $\mathrm{CO}$ adsorption at $110 \mathrm{~K}$ caused the appearance of a predominant IR band at about $2185 \mathrm{~cm}^{-1}$, which is assigned to $\mathrm{CO}$ bound to surface five-fold coordinated $\mathrm{Ti}^{4+}$ sites. ${ }^{48}$ The large blue-shift with respect to the gas-phase value $\left(2143 \mathrm{~cm}^{-1}\right)$ is related to both electrostatic interactions (Stark effect and Pauli repulsion) and electron donation from $\mathrm{CO} 5 \sigma$ orbitals to the surface $\mathrm{Ti}^{4+}$ cations. ${ }^{48} \mathrm{In}-$ terestingly, the frequency typical for $\mathrm{CO}$ bound in the vicinity of $\mathrm{O}$-vacancies on $\mathrm{TiO}_{2}$ surfaces for both, single crystals and powder particles at $2178 \mathrm{~cm}^{-1},{ }_{5}$ was not observed, suggesting that the $\mathrm{TiO}_{2}$ particles were fully oxidized, in line with the XPS observations (see Figure S6). Based on the temperature-dependent IR data and assuming a pre-exponential factor of $10^{13} \mathrm{~s}^{-1}, 66$ the binding energy of $\mathrm{CO}$ was estimated as ca. $40 \mathrm{~kJ} \mathrm{~mol}^{-1}$, revealing a rather weak interaction between $\mathrm{CO}$ and $\mathrm{Ti}^{4+}$. The attenuation of the $2185 \mathrm{~cm}^{-1}$ band is accompanied by a slight blue-shift in frequency (from 2185 to $2200 \mathrm{~cm}^{-1}$ ), which can be $\mathrm{ex}^{-}$ plained in terms of the reduced adsorbate-adsorbate interactions including both dynamic (dipole-dipole coupling) and substrate mediated static effects. ${ }^{67}$ Interestingly, a weak $\mathrm{CO}$ band appears at $2214 \mathrm{~cm}^{-1}$ at elevated temperatures. This band shows a strongly enhanced thermal stability with regard to the $\mathrm{CO}$ species absorbed on regular $\mathrm{Ti}^{4+}$ sites (Figure $4 \mathrm{a}, \mathrm{d}$ and $5 \mathrm{a}, \mathrm{d}, \mathrm{g}$ ). This small band is tentatively assigned to a minority $\mathrm{CO}$ species coadsorbed with carbonates on the $\mathrm{TiO}_{2}$ surfaces. A similar species has been reported in previous works for pure $\mathrm{ZnO}$ and $\mathrm{Au} / \mathrm{ZnO} \mathrm{NPs}{ }^{68-69}$ The existence of carbonate anions, formed probably via $\mathrm{CO}$ oxidation, increases the Lewis acidity of adjacent $\mathrm{Ti}^{4+}$ cations. This effect accounts well for the unexpected enhancement of $\mathrm{CO}$ binding energy and the blue-shift of the $v(\mathrm{CO})$ band. ${ }^{68-69}$

\subsubsection{CO Adsorption on Monometallic Au and Pd NPs Supported on Titania}

Upon $\mathrm{CO}$ adsorption on pure Au NPs supported on $\mathrm{TiO}_{2}$ at $110 \mathrm{~K}$ (see Figure $4 \mathrm{a}-\mathrm{c}$ ), in addition to the intense $\mathrm{TiO}_{2}$ related $\mathrm{CO}$ vibration at $2185 \mathrm{~cm}^{-1}$, a second IR band was observed at $2118 \mathrm{~cm}^{-1}$ being characteristic for CO adsorbed on Au sites. ${ }^{19}, 65,70-74$ The slight red-shift compared to the value of gas-phase CO $\left(2143 \mathrm{~cm}^{-1}\right)$ is typical for CO bound to metals and is attributed to the electron back-donation 
from $\mathrm{Au}$ to the empty $\mathrm{CO} 2 \pi^{*}$ orbital. Temperaturedependent FTIR data provide direct spectroscopic evidence of the thermal stability of different adsorbed species. As shown in Figure $4 \mathrm{~b}, \mathrm{c}$, the $2118 \mathrm{~cm}^{-1}$ band increases first in intensity upon heating to $180 \mathrm{~K}$. This could be related to (i) a restructuring process of the $\mathrm{CO}$
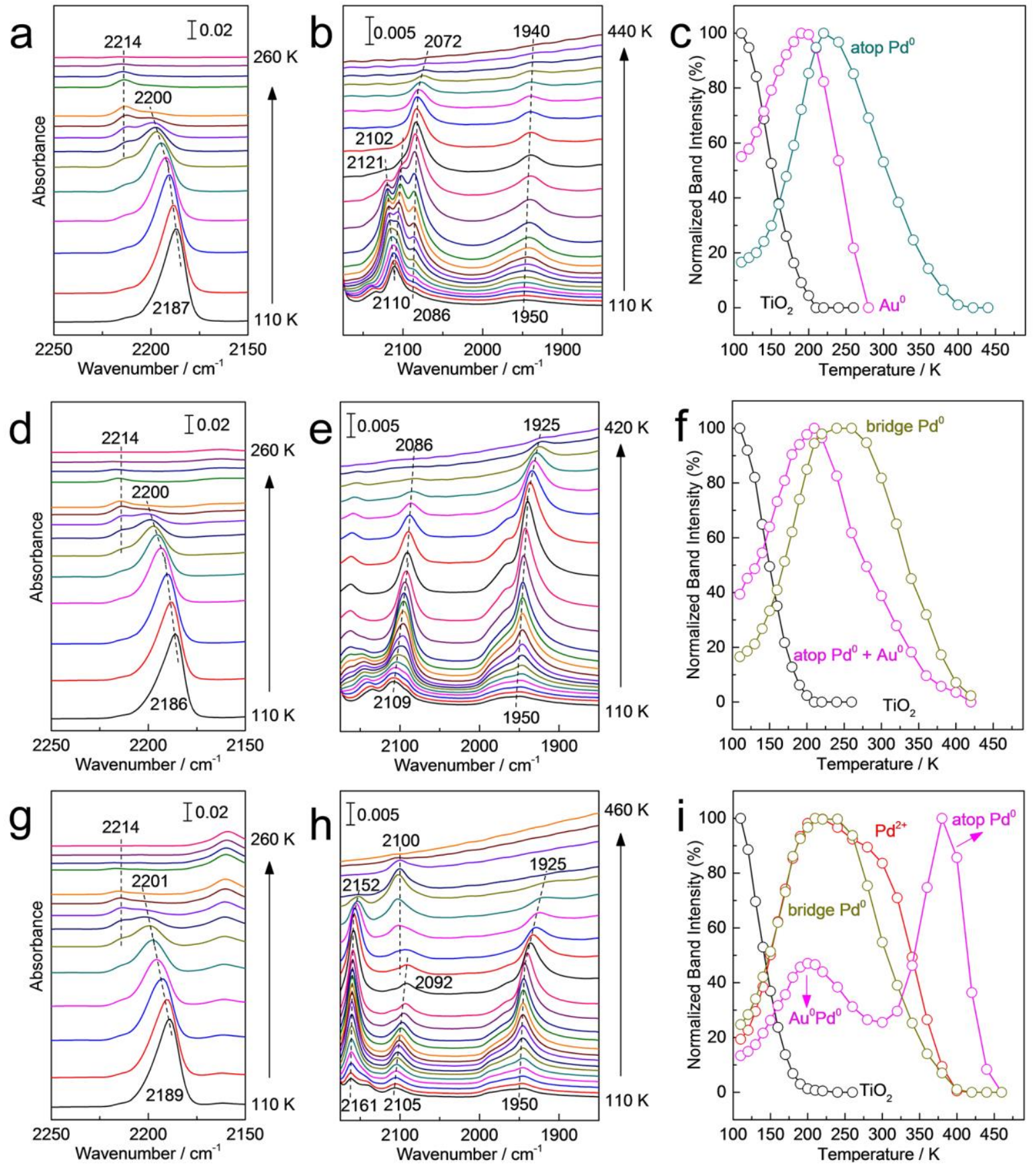

Figure 5. FTIR spectra recorded after exposing the $\mathrm{Au}_{7} \mathrm{Pd}_{3} / \mathrm{TiO}_{2}(\mathrm{a}-\mathrm{c}), \mathrm{Au}_{5} \mathrm{Pd}_{5} / \mathrm{TiO}_{2}$ (d-f) and $\mathrm{Au}_{3} \mathrm{Pd}_{7} / \mathrm{TiO}_{2}$ (g-i) samples to $4 \times 10^{-3}$ mbar $\mathrm{CO}$ at $110 \mathrm{~K}$ and then subsequent gradual heating; (a, d, g) CO- $\mathrm{TiO}_{2}$ region, (b, e, h) CO-AuPd region and (c, f, i) normalized band intensity of the $\mathrm{CO}$ bound to different surface adsorption sites as a function of sample temperature.

adlayer from an inhomogeneous distribution at low temperatures to a more uniform molecular environment and accordingly an increase in ordering and (ii) a thermal diffusion of $\mathrm{CO}$ adsorbed at $\mathrm{Ti}^{4+}$ sites to more stable $\mathrm{Au}$ sites. ${ }^{75}$ Further rise of the temperature leads to a gradual attenuation of the Au-related $\mathrm{CO}$ band with a slight blueshift in frequency from 2118 to $2129 \mathrm{~cm}^{-1}$. According to previous works, the typical band of $\mathrm{CO}$ adsorbed on neu- 
tral $\mathrm{Au}^{\mathrm{o}}$ sites appears at $\sim 2100-2110 \mathrm{~cm}^{-1} .19,65,72-74$ The observed blue-shift for $\mathrm{CO}$ on $\mathrm{Au} / \mathrm{TiO}_{2}$ indicates an electronic modification of surface Au species which is probably caused by the strong interactions between $\mathrm{Au}$ atoms and the $\mathrm{TiO}_{2}$ support at the interfacial sites. We propose that $\mathrm{CO}$ adsorbs preferentially at the low-coordinated $\mathrm{Au}$ sites at $\mathrm{Au} / \mathrm{TiO}_{2}$ interfaces. This $\mathrm{CO}$ species desorbs completely only after increasing the temperature to $260 \mathrm{~K}$, in agreement with published studies. ${ }^{19}$ The corresponding FTIR results obtained for $\mathrm{Pd} / \mathrm{TiO}_{2}$ are displayed in Figure $4 \mathrm{~d}-\mathrm{f}$. $\mathrm{CO}$ adsorption at $110 \mathrm{~K}$ leads to the appearance of a new IR band at $2161 \mathrm{~cm}^{-1}$, which is assigned to $\mathrm{CO}$ bound to positively charged $\mathrm{Pd}^{2+}$. In fact, palladium is mostly oxidized as evidenced by in situ XANES and XPS results (cf. section 3.1 and 3.2, Figure $S_{4 a}$ and Figure 3b). Upon temperature increase to $200 \mathrm{~K}$ (Figure 4e,f), the $2161 \mathrm{~cm}^{-1}$ band gains intensity in parallel to the desorption of $\mathrm{CO}$ on $\mathrm{Ti}^{4+}$ due to the same reasons as discussed above. The $\mathrm{CO}-\mathrm{Pd}^{2+}$ species disappear as the temperature raises further. Interestingly, a weak IR signal at $2100 \mathrm{~cm}^{-1}$ appears and grows at temperatures above $300 \mathrm{~K}$. It is known that $\mathrm{CO}$ molecules bound to specific surface $\mathrm{Pd}^{\circ}$ sites show different vibrational frequencies: typically $2110-2070 \mathrm{~cm}^{-1}$ for linearly (on-top) bonded CO, 2000-1900 $\mathrm{cm}^{-1}$ for 2-fold bridging $\mathrm{CO}$, and $1900-1800 \mathrm{~cm}^{-1}$ for $\mathrm{CO}$ adsorbed on $3^{-}$ fold hollow sites. ${ }^{24}, 36,7^{6}$ Here, the band observed at 2100 $\mathrm{cm}^{-1}$ is characteristic for $\mathrm{CO}$ bound to $\mathrm{Pd}^{\mathrm{o}}$ atop sites. The intensity of this band reaches a maximum at $420 \mathrm{~K}$, while at the same time the $\mathrm{CO}-\mathrm{Pd}^{2+}$ species disappears. This observation suggests that the metallic $\mathrm{Pd}^{\circ}$ is formed by the reduction of surface $\mathrm{Pd}^{2+}$ species via reaction with the $\mathrm{CO}$, i.e. oxidizing the $\mathrm{CO}$ to $\mathrm{CO}_{2}$ by consuming adjacent oxygen species.

\subsubsection{CO Adsorption on Bimetallic $\mathrm{Au}_{\mathrm{x}} \mathrm{Pd}_{\mathrm{y}}(\mathrm{x}: \mathrm{y}=7: 3$,} 1:1, 3:7) NPs Supported on $\mathrm{TiO}_{2}$

Figure 5a-c presents FTIR data obtained after CO adsorption on the bimetallic $\mathrm{Au}_{7} \mathrm{Pd}_{3} / \mathrm{TiO}_{2} \mathrm{NPs}$ at $110 \mathrm{~K}$ and then subsequently heating to higher temperatures. After exposure to $\mathrm{CO}$ at $110 \mathrm{~K}$, one major IR band was observed at $2110 \mathrm{~cm}^{-1}$ in the Au-Pd region apart from the typical bands on titania, as already described above. As the sample temperature increased, the IR band at $2110 \mathrm{~cm}^{-1}$ was split into two components at 2121 and $2102 \mathrm{~cm}^{-1}$, which are attributed to $\mathrm{CO}$ bound to $\mathrm{Au}^{\circ}$ next to $\mathrm{Pd}$ in an on-top configuration and $\mathrm{Au}^{\circ}$-enriched (contiguous) sites, respectively. ${ }^{7}$ Both $\mathrm{CO}$ species desorbed completely upon heating to $\sim 280 \mathrm{~K}$, in line with the thermal stability of Aubonded $\mathrm{CO}$ molecules. The Pd species coordinated to $\mathrm{Au}$ atoms can also be detected, they give rise to the IR feature at $2086 \mathrm{~cm}^{-1}$. This frequency is attributed to $\mathrm{CO}$ adsorbed on-top of $\mathrm{Pd}^{\circ}$ species. The $2086 \mathrm{~cm}^{-1}$ band disappeared only after heating to about $420 \mathrm{~K}$, revealing that $\mathrm{CO}$ adsorbs stronger to $\mathrm{Pd}$ atoms than to Au. Furthermore, this band shifts to $2072 \mathrm{~cm}^{-1}$ with increasing temperature, i.e., with decreasing $\mathrm{CO}$ coverage (Figure $5 \mathrm{~b}$ ). The coveragedependent frequency shift predominantly results from the adsorbate dipole-dipole coupling interactions, typically accompanying $\mathrm{CO}$ adsorption on metal surfaces. ${ }^{77-78}$ The present IR data demonstrated that the $\mathrm{Au}_{7} \mathrm{Pd}_{3} / \mathrm{TiO}_{2}$ sur- face was dominated by the bimetallic $\mathrm{Pd}^{\circ}$ and $\mathrm{Au}^{\circ}$ atoms whereas no $\mathrm{CO}-\mathrm{Pd}^{2+}$ species was observed, in good agreement with the XPS results (see Table 1). Interestingly, on the surface of pure Pd NPs supported on $\mathrm{TiO}_{2}$, only the $\mathrm{CO}$ frequency characteristic for positively charged $\mathrm{Pd}^{2+}$ was observed (Figure $4 \mathrm{e}$ ). These findings suggest that on pure $\mathrm{Pd}$ NPs $\mathrm{O}_{2}$ readily dissociates to form $\mathrm{PdO}_{x}$, which is apparently absent on the alloy NPs. In addition, Figure $5 \mathrm{~b}$ displays a weak and broad feature centered at 1940-1950 $\mathrm{cm}^{-1}$, which is ascribed to CO adsorbed on bridge $\mathrm{Pd}$ sites, indicating the presence of a small amount of contiguous Pd ensembles on the surface. ${ }^{24,36,76,79}$

As discussed in the XPS section, a net Pd to Au charge transfer is anticipated to occur upon alloying according to Pauling's electronegativity scale. However, this intermetallic charge transfer is partially compensated by the enrichment of $\mathrm{Pd}$ d-electrons and the depletion of $\mathrm{Au} \mathrm{d}$ electrons. ${ }^{58,61-63}$ Our IR data provides indirect information about modifications in the electronic structure of the bimetallic Au and Pd species. A lower Au d charge weakens the electron back-donation from $\mathrm{Au}$ into the $\mathrm{CO} 2 \pi^{*}$ orbital and consequently strengthens the $\mathrm{C}-\mathrm{O}$ vibration. In contrast, a red-shift of the $\mathrm{CO}-\mathrm{Pd}^{\circ}$ band takes place due to the charge transfer into the $\mathrm{d}$ bands of Pd. Indeed, the IR band of $\mathrm{CO}$ adsorbed on-top of bimetallic Pd sites was detected at $2086-2072 \mathrm{~cm}^{-1}$ (Figure $5 \mathrm{~b}$ ), which is obviously shifted to lower frequencies compared to that of $\mathrm{CO}$ bound to monometallic Pd atop sites $\left(2100 \mathrm{~cm}^{-1}\right.$, Figure $4 \mathrm{e})$. On the other hand, a blue-shift was observed for bimetallic Au-bonded $\mathrm{CO}\left(\sim 2120 \mathrm{~cm}^{-1}\right)$ with respect to $\mathrm{CO}$ adsorbed at Au-enriched sites $\left(2102 \mathrm{~cm}^{-1}\right.$, Figure $\left.5 \mathrm{~b}\right)$.

The IR spectra obtained after exposing $\mathrm{Au}_{5} \mathrm{Pd}_{5} / \mathrm{TiO}_{2}$ to $\mathrm{CO}$ at $110 \mathrm{~K}$ show a broad band centered at $\sim 2109 \mathrm{~cm}^{-1}$ in the $\mathrm{Au}-\mathrm{Pd}$ region (Figure $5 \mathrm{e}$ ), which is ascribed to mixed $\mathrm{CO}$ species adsorbed on bimetallic $\mathrm{Au}^{\circ}$ and $\mathrm{Pd}^{\circ}$ sites. Again, the intensity of this band reached the maximum at about $200 \mathrm{~K}$ and then gradually decreased with rising temperature, as observed for other samples (Figure 5e,f). At temperatures above $300 \mathrm{~K}$, the $\mathrm{CO}$ band was red-shifted to $2086 \mathrm{~cm}^{-1}$ and disappeared at $420 \mathrm{~K}$, corresponding to the more stable $\mathrm{CO}-\mathrm{Pd}^{\circ}$ species on the bimetallic surface. Additionally, compared with pure Pd (Figure 4e) and Aurich alloy NPs (Figure $5 \mathrm{~b}$ ), the $\mathrm{CO}$ bound to Pd bridge sites becomes a dominating species as evidenced by the intense band at 1950-1925 $\mathrm{cm}^{-1}$. This finding reveals the enrichment of the $\mathrm{Au}_{5} \mathrm{Pd}_{5} / \mathrm{TiO}_{2}$ surface with $\mathrm{Pd}$ giving rise to contiguous $\mathrm{Pd}$ sites, where $\mathrm{CO}$ prefers to bind in a bridging configuration with a higher binding energy (Figure $5 \mathrm{f}$ ). For this sample, the CO-Pd ${ }^{2+}$ species was observed only as a minority species, in line with the XPS results.

The FTIR data of $\mathrm{CO}$ adsorption on Pd-rich $\mathrm{Au}_{3} \mathrm{Pd}_{7} / \mathrm{TiO}_{2}$ are presented in Figure 5g-i. In addition to the $\mathrm{Ti}^{4+}$ related $\mathrm{CO}$ vibration, three intense bands at 2161, 2105 and $1950 \mathrm{~cm}^{-1}$ were observed after exposure to $\mathrm{CO}$ at $110 \mathrm{~K}$ (Figure $5 \mathrm{~h}$ ). They are attributed to $\mathrm{CO}$ adsorbed on positively charged $\mathrm{Pd}^{2+}$, on-top of bimetallic $\mathrm{Au}^{\circ}$ and $\mathrm{Pd}^{\circ}$ sites, as well as bridging on $\mathrm{Pd}^{\circ}$ sites in the $\mathrm{Pd}$-enriched sample, respectively. These assignments are further supported by the thermal stability of various $\mathrm{CO}$ species, which is 
demonstrated by the temperature-dependent IR experiments (Figure 5i). The attenuation of the $\mathrm{CO}$ band at $\sim 2100 \mathrm{~cm}^{-1}$ at temperatures below $300 \mathrm{~K}$ originates predominantly from the desorption of $\mathrm{CO}-\mathrm{Au}$ species because of a relatively weak bonding of $\mathrm{CO}$ to $\mathrm{Au}$. Interestingly, this band shows a second maximum at $380 \mathrm{~K}$, which is accompanied by a complete depletion of the CO-Pd ${ }^{2+}$ species $\left(2161-2152 \mathrm{~cm}^{-1}\right)$, revealing the transformation of $\mathrm{Pd}^{2+}$ to $\mathrm{Pd}^{\circ}$ via $\mathrm{CO}$ oxidation (see above). As shown in Figure $5 \mathrm{~h}$, the corresponding IR band is located at $\sim 2100$ $\mathrm{cm}^{-1}$ being characteristic for $\mathrm{CO}$ bound in atop configuration on monometallic $\mathrm{Pd}^{\circ}$ sites, as observed for $\mathrm{Pd} / \mathrm{TiO}_{2}$ (Figure 4e). These results suggest the coexistence of $\mathrm{Pd}$ enriched and bimetallic Au and Pd sites, in good agreement with the STEM-EDX results showing a segregated contiguous Pd layer around the alloy NPs (Figure 2). The enrichment of the surface with Pd was further supported by the intense $\mathrm{CO}$ band at $1950-1925 \mathrm{~cm}^{-1}$ originating from $\mathrm{CO}$ adsorbed on Pd bridge sites. The catalytic experiments (for details see below) provided evidence that the Pd-rich $\mathrm{Au}_{3} \mathrm{Pd}_{7} / \mathrm{TiO}_{2}$ sample exhibited a higher $\mathrm{CO}$ oxidation activity compared to the other $\mathrm{Au}_{\mathrm{x}} \mathrm{Pd}_{\mathrm{y}} / \mathrm{TiO}_{2}$ catalysts. This could be related to a synergistic effect: the Pdenriched (contiguous) sites activate dioxygen while $\mathrm{CO}$ chemisorbs on both bimetallic Au and Pd sites. It should be noted that the bimetallic Au sites bind $\mathrm{CO}$ weaker than $\mathrm{Pd}$, which is expected to facilitate $\mathrm{CO}$ oxidation at low temperature as the self-poisoning effect can be diminished.

\subsection{CO Oxidation with and without Reductive Pre- treatment in $\mathrm{H}_{2}$}

$\mathrm{Au} / \mathrm{TiO}_{2}, \mathrm{Pd} / \mathrm{TiO}_{2}$ and $\mathrm{AuPd} / \mathrm{TiO}_{2}$ catalysts were tested with respect to $\mathrm{CO}$ oxidation in order to assess their catalytic performance in the reactor and to correlate it to the characteriza-

Table 2 Activation Energies, Turnover Frequencies and Temperature of $50 \%$ CO Conversion for CO Oxidation Tests.

\begin{tabular}{|c|c|c|c|c|c|c|c|c|}
\hline \multirow[t]{2}{*}{ Sample } & \multicolumn{4}{|c|}{ After $\mathrm{N}_{2}$ pre-treatment } & \multicolumn{4}{|c|}{ After $\mathrm{H}_{2}$ pre-treatment } \\
\hline & 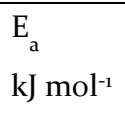 & $\mathrm{TOF}_{313 \mathrm{~K}} \mathrm{~s}^{-}$ & $\begin{array}{l}\mathrm{TOF}_{393 \mathrm{~K}} \\
\mathrm{~s}^{-1}\end{array}$ & $\begin{array}{l}\mathrm{T}_{50 \%} \\
\mathrm{~K}\end{array}$ & $\begin{array}{l}\mathrm{E}_{\mathrm{a}} \\
\mathrm{kJ} \mathrm{mol}^{-1}\end{array}$ & $\mathrm{TOF}_{313 \mathrm{~K}} \mathrm{~s}^{-}$ & $\begin{array}{l}\mathrm{TOF}_{393 \mathrm{~K}} \\
\mathrm{~s}^{-1}\end{array}$ & $\begin{array}{l}\mathrm{T}_{50 \%} \\
\mathrm{~K}\end{array}$ \\
\hline $\mathrm{Au} / \mathrm{TiO}_{2}$ & 29 & 1.1 & 10.3 & 415 & 24 & 1.3 & 8.5 & 391 \\
\hline $\mathrm{Au}_{7} \mathrm{Pd}_{3} / \mathrm{TiO}_{2}$ & 44 & $6.2 \times 10^{-3}$ & $1.9 \times 10^{-1}$ & 435 & 38 & $1.5 \times 10^{-2}$ & $3.0 \times 10^{-1}$ & 417 \\
\hline $\mathrm{Au}_{5} \mathrm{Pd}_{5} / \mathrm{TiO}_{2}$ & 77 & $3.0 \times 10^{-4}$ & $1.1 \times 10^{-1}$ & 428 & 56 & $3.5 \times 10^{-3}$ & $2.8 \times 10^{-1}$ & 408 \\
\hline $\mathrm{Au}_{3} \mathrm{Pd}_{7} / \mathrm{TiO}_{2}$ & 50 & $8.7 \times 10^{-3}$ & $4.3 \times 10^{-1}$ & 412 & 50 & $1.2 \times 10^{-2}$ & $6.2 \times 10^{-1}$ & 402 \\
\hline $\mathrm{Pd} / \mathrm{TiO}_{2}$ & 47 & $6.1 \times 10^{-3}$ & $2.5 \times 10^{-1}$ & 428 & 39 & $1.7 \times 10^{-2}$ & $3.7 \times 10^{-1}$ & 413 \\
\hline
\end{tabular}

tion results discussed above. First pre-treatment in $\mathrm{N}_{2}$ up to $673 \mathrm{~K}$ for $1 \mathrm{~h}$ was applied in order to obtain conditions as close as possible to those during the FTIR measurements, and then the $\mathrm{CO}$ oxidation tests were performed. Afterwards, the samples were reduced in $\mathrm{H}_{2}$ at $523 \mathrm{~K}$ for 1 $\mathrm{h}$, and the $\mathrm{CO}$ oxidation tests were repeated under the same reaction conditions. Figure 6 and $S_{7}$ shows the test results and the corresponding reaction rates $(\mathrm{r}) . \mathrm{Pd} / \mathrm{TiO}_{2}$ and $\mathrm{AuPd} / \mathrm{TiO}_{2}$ started to show low activity above $373 \mathrm{~K}$, whereas the $\mathrm{CO}$ conversion over $\mathrm{Au} / \mathrm{TiO}_{2}$ was $30 \%$ at this temperature. Following a moderate light-off curve, $\mathrm{Au} / \mathrm{TiO}_{2}$ reached full $\mathrm{CO}$ conversion at around $500 \mathrm{~K}$. $\mathrm{Pd} / \mathrm{TiO}_{2}$ and $\mathrm{AuPd} / \mathrm{TiO}_{2}$ catalysts showed a steeper rise in their activities and reached full conversion between 420$450 \mathrm{~K}$ (before $\mathrm{Au} / \mathrm{TiO}_{2}$ ). $\mathrm{H}_{2}$ pre-treatment did not alter the observed trends, although, it improved the performance of the catalysts. Among the bimetallic samples, $\mathrm{Au}_{3} \mathrm{Pd}_{7} / \mathrm{TiO}_{2}$ exhibited the best performance. This differ- 
ence was more pronounced when only $\mathrm{N}_{2}$ had been used for the pre-treatment. Reduction of oxidized metal nanoparticles with $\mathrm{H}_{2}$ enhanced the activities of $\mathrm{Au}_{5} \mathrm{Pd}_{5} / \mathrm{TiO}_{2}$, $\mathrm{Au}_{7} \mathrm{Pd}_{3} / \mathrm{TiO}_{2}$ and $\mathrm{Pd} / \mathrm{TiO}_{2}$ more significantly compared to the $\mathrm{Au}_{3} \mathrm{Pd}_{7} / \mathrm{TiO}_{2}$. The turnover frequencies (TOFs) calculated for the catalysts at $313 \mathrm{~K}$ (extrapolated from Arrhenius plots) and $393 \mathrm{~K}$ are given in Table 2. The TOFs disclose a gradual increase in the order of $\mathrm{Au}_{5} \mathrm{Pd}_{5} / \mathrm{TiO}_{2}<$ $\mathrm{Pd} / \mathrm{TiO}_{2} \leq \mathrm{Au}_{7} \mathrm{Pd}_{3} / \mathrm{TiO}_{2}<\mathrm{Au}_{3} \mathrm{Pd}_{7} / \mathrm{TiO}_{2}<\mathrm{Au} / \mathrm{TiO}_{2}$. Apparent activation energies decreased in the order of $\mathrm{Au}_{5} \mathrm{Pd}_{5} / \mathrm{TiO}_{2}>\mathrm{Au}_{3} \mathrm{Pd}_{7} / \mathrm{TiO}_{2} \geq \mathrm{Pd} / \mathrm{TiO}_{2} \geq \mathrm{Au}_{7} \mathrm{Pd}_{3} / \mathrm{TiO}_{2}>$ $\mathrm{Au} / \mathrm{TiO}_{2}$. Reductive pretreatment increased the $\mathrm{CO}$ oxidation rate and decreased the activation energy $\mathrm{E}_{\mathrm{a}}$. This may be explained by $\mathrm{O}$ vacancies $\left(\mathrm{O}_{\mathrm{v}}\right)$ created in the reducible titania support. ${ }^{80} \mathrm{O}_{\mathrm{v}}$ can have a two effects: on the one hand $\mathrm{O}_{\mathrm{v}}$ facilitate dissociative adsorption of $\mathrm{O}_{2}$, and, on the other hand, they can stronger bind adsorbed $\mathrm{CO}^{81}$ It is well-known that $\mathrm{CO}$ oxidation to $\mathrm{CO}_{2}$ on metallic clusters is governed by adsorption and dissociation of $\mathrm{O}_{2}$ and the binding strength of $\mathrm{CO}^{82-83}$ Since the activation energy of $\mathrm{CO}$ oxidation over $\mathrm{Au}_{5} \mathrm{Pd}_{5} / \mathrm{TiO}_{2}$ and $\mathrm{Au}_{7} \mathrm{Pd}_{3} / \mathrm{TiO}_{2}$ decreased after reductive pretreatment we believe that $\mathrm{CO}$ poisoning ${ }^{84}$ is also decreased (which would contradict stronger adsorption of $\mathrm{CO}$ on $\mathrm{O}_{\mathrm{v}}$ of $\mathrm{TiO}_{2}$ ), therefore dissociation of $\mathrm{O}_{2}$ is rate limiting in this case, similar to the route proposed for $\mathrm{Au} / \mathrm{CeO}_{2} .{ }^{85-86} \mathrm{~A}$ lower degree of $\mathrm{CO}$ poisoning on AuPd alloys compared to pure Pd in the temperature range of interest is supported by the FTIR data (compare Figure $4 \mathrm{f}$ with Figure $5 \mathrm{c}, \mathrm{f}, \mathrm{i}$ ) and firstprinciples calculations. ${ }^{87}$ The catalyst showing the highest synergetic effect of $\mathrm{Au}$ and $\mathrm{Pd}$ (both with and without reductive activation) is exactly the one which shows partial segregation of Pd. Even after the reductive pretreatments monometallic $\mathrm{Pd}^{\circ}$ entities would be oxidized to $\mathrm{PdO}$ under $\mathrm{CO}$ and $\mathrm{O}_{2}$ feed (which is net-oxidizing). $\mathrm{Pd}$ is known to be rapidly reoxidized in the presence of oxygen at intermediate temperatures, i.e. the reductive activation does not stabilize $\mathrm{Pd}^{\circ}$ in the oxidizing atmosphere. ${ }^{88}$ Pd-enriched (contiguous) sites are highly active in dissociative adsorption of $\mathrm{O}_{2}$ while bimetallic AuPd sites also present in the catalyst are responsible for adsorption of $\mathrm{CO}$ without being poisoned at the same time. The activation energies and turnover frequencies over $\mathrm{Au}_{3} \mathrm{Pd}_{7} / \mathrm{TiO}_{2}$ are practically not influenced by the reductive activation. This indicates that $\mathrm{O}_{2}$ activation in this sample occurs on Pd-enriched sites.
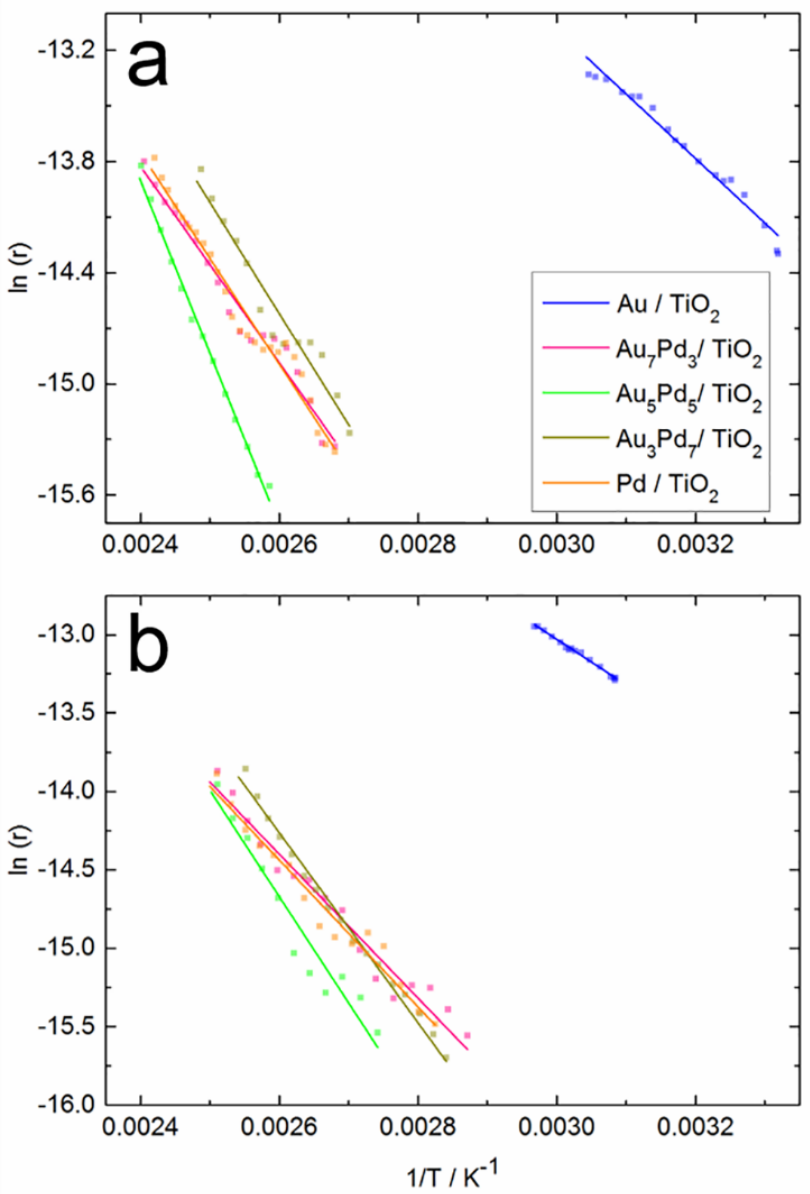

Figure 6. Arrhenius plots for $\mathrm{CO}$ oxidation over $\mathrm{Au} / \mathrm{TiO}_{2}$, $\mathrm{Au}_{3} \mathrm{Pd}_{7} / \mathrm{TiO}_{2}, \quad \mathrm{Au}_{5} \mathrm{Pd}_{5} / \mathrm{TiO}_{2}, \quad \mathrm{Au}_{7} \mathrm{Pd}_{3} / \mathrm{TiO}_{2}$ and $\mathrm{Pd} / \mathrm{TiO}_{2}$ catalysts after (a) $\mathrm{N}_{2}$ and (b) $\mathrm{H}_{2}$ pre-treatment. Conditions: $1000 \mathrm{ppm} \mathrm{CO}, 10 \% \mathrm{O}_{2}$ in $\mathrm{N}_{2}$, GHSV: $48000 \mathrm{~h}^{-1}$ and 1 $\mathrm{K} \mathrm{min}^{-1}$ ramp rate.

These results indicate synergistic effects in the AuPd bimetallic catalysts at higher temperatures, with $\mathrm{Au}_{3} \mathrm{Pd}_{7} / \mathrm{TiO}_{2}$ exhibiting the highest $\mathrm{CO}$ oxidation activity due to AuPd alloyed NPs responsible for adsorption of $\mathrm{CO}$ without being poisoned and activation of $\mathrm{O}_{2}$ molecules by the $\mathrm{Pd}^{2+}$ species. These results confirm the anticipation based on temperature-dependent FTIR data regarding the catalytic performance of such samples.

\section{Conclusions}

Ultrasmall $\mathrm{Au}_{\mathrm{x}} \mathrm{Pd}_{\mathrm{y}}$ (x:y = 1:0, 7:3, 1:1, 3:7 and o:1) NPs with average diameters of $\sim 1 \mathrm{~nm}$ were synthesized in a continuous turbulent flow using a microfluidic reactor. The $\mathrm{Au}_{\mathrm{x}} \mathrm{Pd}_{\mathrm{y}} \mathrm{NPs}$ supported on $\mathrm{TiO}_{2}(\mathrm{P}-25)$ showed some level of aggregation upon deposition, drying and calcination. However, the alloyed $\mathrm{Au}_{\mathrm{x}} \mathrm{Pd}_{\mathrm{y}} / \mathrm{TiO}_{2}$ (especially the $\mathrm{Au}$-rich alloys) showed a narrower size distribution with an average diameter of ca. $5 \mathrm{~nm}$. STEM images and EDX mapping revealed a Pd segregated contiguous layer in the Pd-rich alloy $\left(\mathrm{Au}_{3} \mathrm{Pd}_{7}\right)$. Interestingly, this sample showed the highest synergistic effect in $\mathrm{CO}$ oxidation tests compared to the other bimetallic samples with a steep rise in their 
activities surpassing $\mathrm{Au} / \mathrm{TiO}_{2}$. In situ XANES spectra of the $\mathrm{Pd} / \mathrm{TiO}_{2}$ and $\mathrm{AuPd} / \mathrm{TiO}_{2}$, proved the dominance of oxidized Pd at temperatures between 298 and $673 \mathrm{~K}$ under $\mathrm{N}_{2}$ flow.

The different surface (active) sites $\left(\mathrm{Ti}^{4+}, \mathrm{Pd}^{2+}, \mathrm{Au}^{\circ}\right.$, atop $\mathrm{Pd}^{\circ}$ and bridge $\mathrm{Pd}^{\circ}$ ) of monometallic and bimetallic AuPd NPs dispersed on $\mathrm{TiO}_{2}$ powders were identified by temperature-dependent FTIR spectroscopy using $\mathrm{CO}$ as a probe molecule. The surfaces of pure $\mathrm{Au}$ and $\mathrm{Pd}$ particles mostly consists of neutral $\mathrm{Au}$ and positively charged $\mathrm{Pd}^{2+}$, respectively. Upon alloying, the bimetallic $\mathrm{Au}^{\circ}$ and $\mathrm{Pd}^{\circ}$ sites become the major surface species while depending on the Au:Pd ratio, the Au-enriched and Pd-enriched components were also detected. The combined IR and XPS results demonstrated strong electronic interactions between $\mathrm{Au}$ and $\mathrm{Pd}$, which likely result from an interatomic charge transfer and electronic modifications in the $\mathrm{d}$ bands of $\mathrm{Au}$ and $\mathrm{Pd}$. A synergistic effect accounts for the higher activity of the $\mathrm{Au}_{3} \mathrm{Pd}_{7} / \mathrm{TiO}_{2}$ sample for $\mathrm{CO}$ oxidation to $\mathrm{CO}_{2}$, in which the Pd-enriched sites are responsible for the activation of molecular oxygen while both bimetallic Au and Pd sites chemisorb CO. The interaction between metal NPs and support is known to play a crucial role in NP stabilization and the catalytic performance. The titania phase, surface crystallographic plane and defects are crucial parameters. ${ }^{89-90}$ The influence of $\mathrm{TiO}_{2}$ support on the catalytic activity of AuPd nanoalloys would thus be an interesting topic for future studies.

\section{AUTHOR INFORMATION}

\section{Corresponding Authors}

* E-mail: yuemin.wang@kit.edu (Y.W.)

* E-mail: grunwaldt@kit.edu (J.-D.G.)

Tel.: +49 $721608-42120$

Fax: $+49721608-44820$

\section{Author Contributions}

The manuscript was written through contributions of all authors. All authors have given approval to the final version of the manuscript. $+(G . T$.$) and (X.Y.) contributed equally.$

\section{Funding Sources}

Virtual Institute VI-403 "In-situ Nano Imaging of Biological and Chemical Processes"; BMBF (projects $0_{5} \mathrm{~K}_{10 V K}$, o5 $\mathrm{K}_{13} \mathrm{VK}_{2}$ );

"Science and Technology of Nanosystems" Programme (432202)

China Scholarship Council

\section{ASSOCIATED CONTENT}

Supporting Information. Nanoparticle aggregation during deposition on supports and calcination. STEM images and size distributions of $\mathrm{Au}_{\mathrm{x}} \mathrm{Pd}_{\mathrm{y}} / \mathrm{TiO}_{2}$. HRTEM images of supported nanoparticles on titania. In situ and ex situ XANES spectra, XPS data, CO oxidation tests.

\section{ACKNOWLEDGMENTS}

The Virtual Institute VI-403 "In-situ Nano Imaging of Biological and Chemical Processes", the BMBF (projects o5K1oVK1, $\mathrm{o}_{5} \mathrm{~K}_{13} \mathrm{VK}_{2}$ ), "Science and Technology of Nanosystems" Programme (432202) and KIT are gratefully acknowledged for financial support. In addition, we would like to appreciate the Karlsruhe Nano Micro Facility (KNMF), a Helmholtz research infrastructure at KIT for providing STEM-EDX measurements. Xiaojuan $\mathrm{Yu}$ thanks the $\mathrm{PhD}$ fellowships sponsored by the China Scholarship Council. Finally, we thank the CAT-ACT beamline at the KIT synchrotron for providing beamtime, in particular Dr. Tim Prüßmann and Dr. Anna Zimina (IKFT) for their help and technical support during XAS experiments.

\section{REFERENCES}

(1) Yao, Q.; Wang, C.; Wang, H.; Yan, H.; Lu, J. Revisiting the Au Particle Size Effect on $\mathrm{TiO}_{2}$-Coated $\mathrm{Au} / \mathrm{TiO}_{2}$ Catalysts in CO Oxidation Reaction. J. Phys. Chem. C 2016, 120, 9174-9183.

(2) Zwijnenburg, A.; Goossens, A.; Sloof, W. G.; Crajé, M. W.; van der Kraan, A. M.; Jos de Jongh, L.; Makkee, M.; Moulijn, J. A. XPS and Mössbauer Characterization of $\mathrm{Au} / \mathrm{TiO}_{2}$ Propene Epoxidation Catalysts. J. Phys. Chem. B 20o2, 106, 9853-9862.

(3) Hammer, B.; Norskov, J. Why Gold is the Noblest of All the Metals. Nature 1995, 376, 238-240.

(4) Meyer, R.; Lemire, C.; Shaikhutdinov, S. K.; Freund, H.J. Surface Chemistry of Catalysis by Gold. Gold Bull. 2oo4, 37, 72124 .

(5) Villa, A.; Wang, D.; Su, D. S.; Prati, L. New Challenges in Gold Catalysis: Bimetallic Systems. Catal. Sci. Technol. 2015, 5, $55-68$.

(6) Haruta, M.; Tsubota, S.; Kobayashi, T.; Kageyama, H.; Genet, M. J.; Delmon, B. Low-Temperature Oxidation of CO over Gold Supported on $\mathrm{TiO}_{2}, \alpha-\mathrm{Fe}_{2} \mathrm{O}_{3}$, and $\mathrm{Co}_{3} \mathrm{O}_{4}$. J. Catal. 1993, 144, 175-192.

(7) Haruta, M.; Yamada, N.; Kobayashi, T.; Iijima, S. Gold Catalysts Prepared by Coprecipitation for Low-Temperature Oxidation of Hydrogen and of Carbon Monoxide. J. Catal. 1989, 115, 301-309.

(8) Tsubota, S.; Nakamura, T.; Tanaka, K.; Haruta, M. Effect of Calcination Temperature on the Catalytic Activity of $\mathrm{Au}$ Colloids Mechanically Mixed with $\mathrm{TiO}_{2}$ Powder for CO Oxidation. Catal. Lett. 1998, 56, 131-135.

(9) Haruta, M.; Uphade, B.; Tsubota, S.; Miyamoto, A. Selective Oxidation of Propylene over Gold Deposited on Titanium-Based Oxides. Res. Chem. Intermediat. 1998, 24, 329-336.

(10) Uphade, B.; Tsubota, S.; Hayashi, T.; Haruta, M., Selective Oxidation of Propylene to Propylene Oxide or Propionaldehyde over Au Supported on Titanosilicates in the Presence of $\mathrm{H}_{2}$ and $\mathrm{O}_{2}$. Chem. Lett. 1998, 27, 1277-1278.

(11) Hashmi, A. S. K.; Hutchings, G. J. Gold Catalysis. Angew. Chem. Int. Ed. 20o6, 45, 7896-7936.

(12) Sandoval, A.; Gómez-Cortés, A.; Zanella, R.; Díaz, G.; Saniger, J. M. Gold Nanoparticles: Support Effects for the WGS Reaction. J. Mol. Catal. A Chem. 2007, 278, 200-208.

(13) Ueda, A.; Oshima, T.; Haruta, M. Reduction of Nitrogen Monoxide with Propene in the Presence of Oxygen and Moisture over Gold Supported on Metal Oxides. Appl. Catal. B Environ. 1997, 12, 81-93.

(14) Bollinger, M. J.; Sievers, R. E.; Fahey, D. W.; Fehsenfeld, F. C. Conversion of Nitrogen Dioxide, Nitric Acid, and nPropyl Nitrate to Nitric Oxide by a Gold-Catalyzed Reduction with Carbon Monoxide. Anal. Chem. 1983, 55, 1980-1986.

(15) Corma, A.; Garcia, H. Supported Gold Nanoparticles as Catalysts for Organic Reactions. Chem. Soc. Rev. 20o8, 37, 20962126. 
(16) Tsunoyama, H.; Ichikuni, N.; Sakurai, H.; Tsukuda, T., Effect of electronic structures of Au clusters stabilized by poly (N-vinyl-2-pyrrolidone) on aerobic oxidation catalysis. J. Am. Chem. Soc. 2009, 131 (20), 7086-7093.

(17) Tsunoyama, H.; Ichikuni, N.; Tsukuda, T. Microfluidic Synthesis and Catalytic Application of PVP-Stabilized, $1 \mathrm{~nm}$ Gold Clusters. Langmuir 2008, 24, 11327-11330.

(18) Janssens, T. V.; Carlsson, A.; Puig-Molina, A.; Clausen, B. S. Relation Between Nanoscale Au Particle Structure and Activity for CO Oxidation on Supported Gold Catalysts. J. Catal. 2006, 240, 108-113.

(19) Green, I. X.; Tang, W.; Neurock, M.; Yates, J. T. Spectroscopic Observation of Dual Catalytic Sites During Oxidation of $\mathrm{CO}$ on a $\mathrm{Au} / \mathrm{TiO}_{2}$ Catalyst. Science 2o11, 333, 736-739.

(20) Ferrando, R.; Jellinek, J.; Johnston, R. L. Nanoalloys: from Theory to Applications of Alloy Clusters and Nanoparticles. Chem. Rev. 2008, 108, 845-910.

(21) Chaki, N. K.; Tsunoyama, H.; Negishi, Y.; Sakurai, H.; Tsukuda, T. Effect of Ag-Doping on the Catalytic Activity of Polymer-Stabilized Au Clusters in Aerobic Oxidation of Alcohol. J. Phys. Chem. C 2007, 111, 4885-4888.

(22) Marx, S.; Baiker, A. Beneficial Interaction of Gold and Palladium in Bimetallic Catalysts for the Selective Oxidation of Benzyl Alcohol. J. Phys. Chem. C 2009, 113, 6191-6201.

(23) Tsen, S.-C.; Crozier, P.; Liu, J. Lattice Measurement and Alloy Compositions in Metal and Bimetallic Nanoparticles. Ultramicroscopy 2003, 98, 63-72.

(24) Hanrieder, E. K.; Jentys, A.; Lercher, J. A. Atomistic Engineering of Catalyst Precursors: Dynamic Reordering of PdAu Nanoparticles During Vinyl Acetate Synthesis Enhanced by Potassium Acetate. ACS Catal. 2015, 5, 5776-5786.

(25) Han, Y.-F.; Wang, J.-H.; Kumar, D.; Yan, Z.; Goodman, D. A Kinetic Study of Vinyl Acetate Synthesis over Pd-Based Catalysts: Kinetics of Vinyl Acetate Synthesis over $\mathrm{Pd}-\mathrm{Au} / \mathrm{SiO}_{2}$ and $\mathrm{Pd} / \mathrm{SiO}_{2}$ Catalysts. J. Catal. 20o5, 232, 467-475.

(26) Edwards, J. K.; Solsona, B. E.; Landon, P.; Carley, A. F.; Herzing, A.; Kiely, C. J.; Hutchings, G. J. Direct Synthesis of Hydrogen Peroxide from $\mathrm{H}_{2}$ and $\mathrm{O}_{2}$ Using $\mathrm{TiO}_{2}$-Supported $\mathrm{Au}-\mathrm{Pd}$ Catalysts. J. Catal. 2005, 236, 69-79.

(27) Edwards, J. K.; Solsona, B.; Ntainjua, E.; Carley, A. F.; Herzing, A. A.; Kiely, C. J.; Hutchings, G. J. Switching off Hydrogen Peroxide Hydrogenation in the Direct Synthesis Process. Science 2009, 323, 1037-1041.

(28) Edwards, J. K.; Freakley, S. J.; Carley, A. F.; Kiely, C. J.; Hutchings, G. J. Strategies for Designing Supported GoldPalladium Bimetallic Catalysts for the Direct Synthesis of Hydrogen Peroxide. Acc. Chem. Res. 2013, 47, 845-854.

(29) Dimitratos, N.; Lopez-Sanchez, J. A.; Hutchings, G. J. Selective Liquid Phase Oxidation with Supported Metal Nanoparticles. Chem. Sci. 2012, 3, 20-44.

(30) Griffin, M. B.; Rodriguez, A. A.; Montemore, M. M.; Monnier, J. R.; Williams, C. T.; Medlin, J. W. The Selective Oxidation of Ethylene Glycol and 1, 2-Propanediol on Au, Pd, and $\mathrm{Au}-\mathrm{Pd}$ Bimetallic Catalysts. J. Catal. 2013, 307, 111-120.

(31) Davis, S. E.; Ide, M. S.; Davis, R. J. Selective Oxidation of Alcohols and Aldehydes over Supported Metal Nanoparticles. Green Chem. 2013, 15, 17-45.

(32) Ksar, F.; Ramos, L.; Keita, B.; Nadjo, L.; Beaunier, P.; Remita, H. Bimetallic Palladium-Gold Nanostructures: Application in Ethanol Oxidation. Chem. Mater. 2009, 21, 3677-3683.

(33) Collins, N. R.; Twigg, M. V. Three-Way Catalyst Emissions Control Technologies for Spark-Ignition Engines-Recent Trends and Future Developments. Top. Catal. 20o7, 42, 323-332.

(34) Xu, J.; White, T.; Li, P.; He, C.; Yu, J.; Yuan, W.; Han, Y.-F. Biphasic Pd-Au Alloy Catalyst for Low-Temperature CO Oxidation. J. Am. Chem. Soc. 2010, 132, 10398-10406.
(35) Venezia, A.; Liotta, L.; Pantaleo, G.; La Parola, V.; Deganello, G.; Beck, A.; Koppány, Z.; Frey, K.; Horvath, D.; Guczi, L. Activity of $\mathrm{SiO}_{2}$ Supported Gold-Palladium Catalysts in CO Oxidation. Appl. Catal. A Gen. 2003, 251, 359-368.

(36) Gao, F.; Wang, Y.; Goodman, D. W. CO Oxidation over AuPd (100) from Ultrahigh Vacuum to near-Atmospheric Pressures: the Critical Role of Contiguous Pd Atoms. J. Am. Chem. Soc. 2009, 131, 5734-5735.

(37) Ishizaka, T.; Ishigaki, A.; Kawanami, H.; Suzuki, A.; Suzuki, T. M. Dynamic Control of Gold Nanoparticle Morphology in a Microchannel Flow Reactor by Glucose Reduction in Aqueous Sodium Hydroxide Solution. J. Colloid Interface Sci. 2012, $367,135-138$

(38) Köhler, J.; Abahmane, L.; Wagner, J.; Albert, J.; Mayer, G. Preparation of Metal Nanoparticles with Varied Composition for Catalytical Applications in Microreactors. Chem. Eng. Sci. 2008, 63, 5048-5055.

(39) Knauer, A.; Thete, A.; Li, S.; Romanus, H.; Csaki, A.; Fritzsche, W.; Köhler, J. Au/Ag/Au Double Shell Nanoparticles with Narrow Size Distribution Obtained by Continuous Micro Segmented Flow Synthesis. Chem. Eng. J. 2011, 166, 1164-1169.

(40) Hayashi, N.; Sakai, Y.; Tsunoyama, H.; Nakajima, A. Development of Ultrafine Multichannel Microfluidic Mixer for Synthesis of Bimetallic Nanoclusters: Catalytic Application of Highly Monodisperse AuPd Nanoclusters Stabilized by Poly (Nvinylpyrrolidone). Langmuir 2014, 30, 10539-10547.

(41) Tofighi, G.; Gaur, A.; Doronkin, D. E.; Lichtenberg, H.; Wang, W.; Wang, D.; Rinke, G.; Ewinger, A.; Dittmeyer, R.; Grunwaldt, J.-D. Microfluidic Synthesis of Ultrasmall AuPd Nanoparticles with a Homogeneously Mixed Alloy Structure in Fast Continuous Flow for Catalytic Applications. J. Phys. Chem. C 2018, 122, 1721-1731.

(42) Tofighi, G. A Microfluidic Reactor for Time and Spatially Resolved in situ Spectroscopic Studies on Nanoparticles During Synthesis. Ph.D. Dissertation, Karlsruhe Institute of Technology, Germany, 2018.

(43) Yang, C.; Wöll, C. IR Spectroscopy Applied to Metal Oxide Surfaces: Adsorbate Vibrations and Beyond. Adv. Phys. X 2017, 2, 373-408.

(44) Tofighi, G.; Lichtenberg, H.; Pesek, J.; Sheppard, T. L.; Wang, W.; Schottner, L.; Rinke, G.; Dittmeyer, R.; Grunwaldt, J.D. Continuous Microfluidic Synthesis of Colloidal Ultrasmall Gold Nanoparticles: In Situ Study of the Early Reaction Stages and Application for Catalysis. React. Chem. Eng. 2017, 2, 876-884

(45) Schneider, C. A.; Rasband, W. S.; Eliceiri, K. W. NIH Image to ImageJ: 25 Years of Image Analysis. Nat. Methods 2012, 9, 671-675.

(46) Zimina, A.; Dardenne, K.; Denecke, M. A.; Doronkin, D. E.; Huttel, E.; Lichtenberg, H.; Mangold, S.; Pruessmann, T.; Rothe, J.; Spangenberg, T.; Steininger, R.; Vitova, T.; Geckeis, H.; Grunwaldt, J.-D. CAT-ACT-A New Highly Versatile X-Ray Spectroscopy Beamline for Catalysis and Radionuclide Science at the KIT Synchrotron Light Facility ANKA. Rev. Sci. Instrum. 2017, 88, 113113.

(47) Ravel, B.; Newville, M. ATHENA, ARTEMIS, HEPHAESTUS: Data Analysis for X-Ray Absorption Spectroscopy Using IFEFFIT. J. Synchrotron Radiat. 2005, 12, 537-541.

(48) Wang, Y.; Wöll, C. IR Spectroscopic Investigations of Chemical and Photochemical Reactions on Metal Oxides: Bridging the Materials Gap. Chem. Soc. Rev. 2017, 46, 1875-1932.

(49) Yu, X.; Zhang, Z.; Yang, C.; Bebensee, F.; Heissler, S.; Nefedov, A.; Tang, M.; Ge, Q.; Chen, L.; Kay, B. D. Interaction of Formaldehyde with the Rutile $\mathrm{TiO}_{2}$ (110) Surface: A Combined Experimental and Theoretical Study. J. Phys. Chem. C 2016, 120, 12626-12636. 
(5o) Doniach, S.; Sunjic, M. Many-Electron Singularity in XRay Photoemission and X-Ray Line Spectra from Metals. J. Phys. C Solid State Phys. 1970, 3, 285.

(51) Scofield, J. H. Hartree-Slater Subshell Photoionization Cross-Sections at 1254 and $1487 \mathrm{eV}$. J. Electron Spectrosc. and Related Phenomena 1976, 8, 129-137.

(52) Maeland, A.; Flanagan, T. B. Lattice Spacings of GoldPalladium Alloys. Can. J. Phys. 1964, 42, 2364-2366.

(53) Liu, C.; Chen, N.; Li, J.; Gao, X.; Sham, T.-K.; Wang, S.D. Fingerprint Feature of Atomic Intermixing in Supported AuPd Nanocatalysts Probed by X-Ray Absorption Fine Structure. J. Phys. Chem. C 2017, 121, 28385-28394.

(54) Arrigo, R.; Schuster, M. E.; Abate, S.; Wrabetz, S.; Amakawa, K.; Teschner, D.; Freni, M.; Centi, G.; Perathoner, S.; Hävecker, M. Dynamics of Palladium on Nanocarbon in the Direct Synthesis of $\mathrm{H}_{2} \mathrm{O}_{2}$. ChemSusChem 2014, 7, 179-194.

(55) Wang, H.-F.; Kaden, W. E.; Dowler, R.; Sterrer, M.; Freund, H.-J. Model Oxide-Supported Metal CatalystsComparison of Ultrahigh Vacuum and Solution Based Preparation of Pd Nanoparticles on a Single-Crystalline Oxide Substrate. Phys. Chem. Chem. Phys. 2012, 14, 11525-11533.

(56) Zemlyanov, D.; Aszalos-Kiss, B.; Kleimenov, E.; Teschner, D.; Zafeiratos, S.; Hävecker, M.; Knop-Gericke, A.; Schlögl, R.; Gabasch, H.; Unterberger, W. In Situ XPS Study of Pd (111) Oxidation. Part 1: 2D Oxide Formation in $10^{-3} \mathrm{mbar}_{2}$. Surf. Sci. 2006, 600, 983-994.

(57) Gabasch, H.; Unterberger, W.; Hayek, K.; Klötzer, B.; Kleimenov, E.; Teschner, D.; Zafeiratos, S.; Hävecker, M.; KnopGericke, A.; Schlögl, R. In Situ XPS Study of Pd (111) Oxidation at Elevated Pressure, Part 2: Palladium Oxidation in the $10^{-1} \mathrm{mbar}$ Range. Surf. Sci. 2006, 600, 2980-2989.

(58) Rodriguez, J.; Goodman, D. W. The Nature of the Metal-Metal Bond in Bimetallic Surfaces. Science 1992, 257, 897-903.

(59) Li, Z.; Gao, F.; Furlong, O.; Tysoe, W. T. Adsorption of Carbon Monoxide Au/Pd (100) Alloys in Ultrahigh Vacuum: Identification of Adsorption Sites. Surf. Sci. 2010, 604, 136-143.

(6o) Li, Z.; Gao, F.; Wang, Y.; Calaza, F.; Burkholder, L.; Tysoe, W. T. Formation and Characterization of Au/Pd Surface Alloys on Pd (111). Surf. Sci. 2007, 601, 1898-19o8.

(61) Gao, F.; Goodman, D. W. Pd-Au Bimetallic Catalysts: Understanding Alloy Effects from Planar Models and (Supported) Nanoparticles. Chem. Soc. Rev. 2012, 41, 8009-8020.

(62) Rodriguez, J. Physical and Chemical Properties of Bimetallic Surfaces. Surf. Sci. Rep. 1996, 24, 223-287.

(63) Lee, Y.-S.; Jeon, Y.; Chung, Y.-D.; Lim, K.-Y.; Whang, C.-N.; Oh, S.-J. Charge Redistribution and Electronic Behavior in Pd-Au Alloys. J. Korean Phys. Soc. 2ooo, 37, 451-455.

(64) Wang, D.; Cui, X.; Xiao, Q.; Hu, Y.; Wang, Z.; Yiu, Y. M.; Sham, T. K. Electronic Behaviour of Au-Pt Alloys and the $4 \mathrm{f}$ Binding Energy Shift Anomaly in Au Bimetallics-X-Ray Spectroscopy Studies. AIP Adv. 2018, 8, o65210.

(65) Xu, M.; Noei, H.; Fink, K.; Muhler, M.; Wang, Y.; Wöll, C. The Surface Science Approach for Understanding Reactions on Oxide Powders: the Importance of IR Spectroscopy. Angew. Chem. Int. Ed. 2012, 51, 4731-4734.

(66) Redhead, P. Thermal Desorption of Gases. Vacuum 1962, 12, 203-211.

(67) Buchholz, M.; Yu, X.; Yang, C.; Heißler, S.; Nefedov, A.; Wang, Y.; Wöll, C. IR-Spectroscopy of CO Adsorption on MixedTerminated ZnO Surfaces. Surf. Sci. 2016, 652, 247-252.

(68) Noei, H.; Birkner, A.; Merz, K.; Muhler, M.; Wang, Y. Probing the Mechanism of Low-Temperature CO Oxidation on $\mathrm{Au} / \mathrm{ZnO}$ Catalysts by Vibrational Spectroscopy. J. Phys. Chem. C 2012, 116, 11181-11188.

(69) Wang, Y.; Xia, X.; Urban, A.; Qiu, H.; Strunk, J.; Meyer, B.; Muhler, M.; Wöll, C. Tuning the Reactivity of Oxide Surfaces by Charge-Accepting Adsorbates. Angew. Chem. Int. Ed. 2007, 46, 7315-7318.

(70) Meier, D. C.; Goodman, D. W. The Influence of Metal Cluster Size on Adsorption Energies: CO Adsorbed on Au Clusters Supported on $\mathrm{TiO}_{2}$. J. Am. Chem. Soc. 2004, 126, 1892-1899.

(71) Dekkers, M.; Lippits, M.; Nieuwenhuys, B. CO Adsorption and Oxidation on $\mathrm{Au} / \mathrm{TiO}_{2}$. Catal. Lett. 1998, 56, 195-197.

(72) Grunwaldt, J.-D.; Maciejewski, M.; Becker, O. S.; Fabrizioli, P.; Baiker, A. Comparative Study of $\mathrm{Au} / \mathrm{TiO}_{2}$ and $\mathrm{Au} / \mathrm{ZrO}_{2}$ Catalysts for Low-Temperature CO Oxidation. J. Catal. 1999, 186, 458-469.

(73) Boccuzzi, F.; Chiorino, A.; Manzoli, M. FTIR Study of the Electronic Effects of CO Adsorbed on Gold Nanoparticles Supported on Titania. Surf. Sci. 2ooo, 454, 942-946.

(74) Hartshorn, H.; Pursell, C. J.; Chandler, B. D. Adsorption of CO on Supported Gold Nanoparticle Catalysts: a Comparative Study. J. Phys. Chem. C 2009, 113, 10718-10725.

(75) Yang, C.; Yu, X.; Heißler, S.; Nefedov, A.; Colussi, S.; Llorca, J.; Trovarelli, A.; Wang, Y.; Wöll, C. Surface Faceting and Reconstruction of Ceria Nanoparticles. Angew. Chem. Int. Ed. 2017, 56, 375-379.

(76) Abbott, H. L.; Aumer, A.; Lei, Y.; Asokan, C.; Meyer, R. J.; Sterrer, M.; Shaikhutdinov, S.; Freund, H.-J. CO Adsorption on Monometallic and Bimetallic Au-Pd Nanoparticles Supported on Oxide Thin Films. J. Phys. Chem. C 2010, 114, 17099-17104.

(77) Crossley, A.; King, D. A. Infrared Spectra for CO Isotopes Chemisorbed on Pt "111": Evidence for Strong Absorbate Coupling Interactions. Surf. Sci. 1977, 68, 528-538.

(78) Persson, B.; Ryberg, R. Vibrational Interaction Between Molecules Adsorbed on a Metal Surface: the Dipole-Dipole Interaction. Phys. Rev. B 1981, 24, 6954.

(79) Muglali, M. I.; Liu, J.; Bashir, A.; Borissov, D.; Xu, M.; Wang, Y.; Wöll, C.; Rohwerder, M. On the Complexation Kinetics for Metallization of Organic Layers: Palladium onto a Pyridine-Terminated Araliphatic Thiol Film. Phys. Chem. Chem. Phys. 2012, 14, 4703-4712.

(8o) Wang, G.; Wang, H.; Ling, Y.; Tang, Y.; Yang, X.; Fitzmorris, R. C.; Wang, C.; Zhang, J. Z.; Li, Y. Hydrogen-Treated $\mathrm{TiO}_{2}$ Nanowire Arrays for Photoelectrochemical Water Splitting. Nano Lett. 2011, 11, 3026-3033.

(81) Wendt, S.; Schaub, R.; Matthiesen, J.; Vestergaard, E. K.; Wahlström, E.; Rasmussen, M. D.; Thostrup, P.; Molina, L.; Lægsgaard, E.; Stensgaard, I. Oxygen Vacancies on $\mathrm{TiO}_{2}$ (110) and their Interaction with $\mathrm{H}_{2} \mathrm{O}$ and $\mathrm{O}_{2}$ : a Combined High-Resolution STM and DFT Study. Surf. Sci. 2005, 598, 226-245.

(82) Lang, S. M.; Fleischer, I.; Bernhardt, T. M.; Barnett, R. N.; Landman, U. Low-Temperature CO Oxidation Catalyzed by Free Palladium Clusters: Similarities and Differences to Pd Surfaces and Supported Particles. ACS Catal. 2015, 5, 2275-2289.

(83) Song, W.; Su, Y.; Hensen, E. J. A DFT Study of CO Oxidation at the $\mathrm{Pd}-\mathrm{CeO}_{2}$ (110) Interface. J. Phys. Chem. C 2015, 119, 27505-27511.

(84) Kunz, S.; Schweinberger, F. F.; Habibpour, V.; Röttgen, M.; Harding, C.; Arenz, M.; Heiz, U. Temperature Dependent CO Oxidation Mechanisms on Size-Selected Clusters. J. Phys. Chem. C 2009, 114, 1651-1654.

(85) Kim, H. Y.; Lee, H. M.; Henkelman, G. CO Oxidation Mechanism on $\mathrm{CeO}_{2}$-Supported Au Nanoparticles. J. Am. Chem. Soc. 2012, 134, 1560-1570.

(86) Song, W.; Hensen, E. J. A Computational DFT Study of CO Oxidation on a Au Nanorod Supported on $\mathrm{CeO}_{2}$ (110): on the Role of the Support Termination. Catal. Sci. Technol. 2013, 3, 3020-3029.

(87) Zhang, J.; Alexandrova, A. N. The Golden Crown: a Single Au Atom that Boosts the CO Oxidation Catalyzed by a Palladium Cluster on Titania Surfaces. J. Phys. Chem. Lett. 2013, 4, 2250-2255. 
(88) Lang, S. M.; Fleischer, I.; Bernhardt, T. M.; Barnett, R. N.; Landman, U. Size-Dependent Self-Limiting Oxidation of Free Palladium Clusters. J. Phys. Chem. A 2014, 118, 8572-8582.

(89) Zhou, Y.; Doronkin, D. E.; Chen, M.; Wei, S.; Grunwaldt, J.-D. Interplay of Pt and Crystal Facets of $\mathrm{TiO}_{2}$ : CO Oxidation Activity and Operando XAS/DRIFTS Studies. ACS Catal. 2016, 6, 7799-7809.

(90) Yogi, C.; Kojima, K.; Hashishin, T.; Wada, N.; Inada, Y.; Della Gaspera, E.; Bersani, M.; Martucci, A.; Liu, L.; Sham, T.-K. Size Effect of $\mathrm{Au}$ Nanoparticles on $\mathrm{TiO}_{2}$ Crystalline Phase of NanoComposite Thin Films and their Photocatalytic Properties. J. Phys. Chem. C 2011, 115, 6554-656o. 
Table of Contents artwork

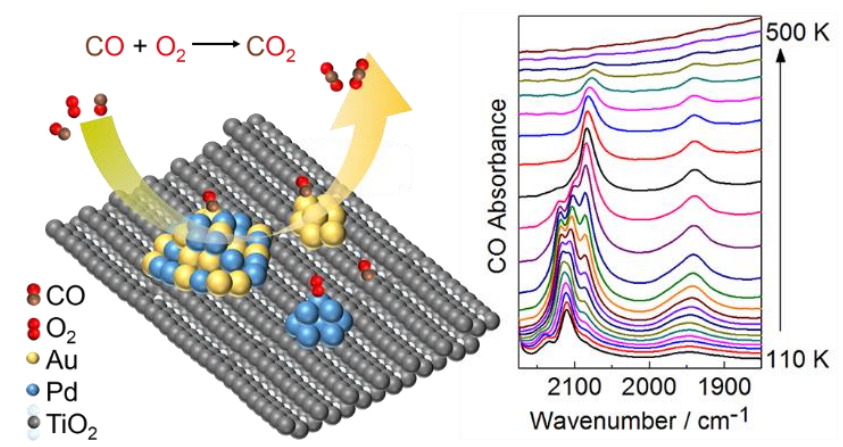

